NBER WORKING PAPER SERIES

\title{
INTENDED AND UNINTENDED EFFECTS OF E-CIGARETTE TAXES ON YOUTH TOBACCO USE
}

\author{
Rahi Abouk \\ Charles J. Courtemanche \\ Dhaval M. Dave \\ Bo Feng \\ Abigail S. Friedman \\ Johanna Catherine Maclean \\ Michael F. Pesko \\ Joseph J. Sabia \\ Samuel Safford \\ Working Paper 29216 \\ http://www.nber.org/papers/w29216 \\ NATIONAL BUREAU OF ECONOMIC RESEARCH \\ 1050 Massachusetts Avenue \\ Cambridge, MA 02138 \\ September 2021, Revised October 2022
}

Author order is alphabetic and lead authorship is shared amongst all the authors. Research reported in this publication was supported by the National Institute on Drug Abuse of the National Institutes of Health under award number R01DA045016 (PI: Michael Pesko), R01DA039968 (PI: Dhaval Dave), and an Evidence for Action grant from the Robert Wood Johnson Foundation (grant \#74869; PI: Friedman). Dr. Sabia acknowledges support from San Diego State University's Center for Health Economics \& Policy Studies (CHEPS), Dr. Courtemanche acknowledges support from the University of Kentucky's Institute for the Study of Free Enterprise, and Dr. Abouk acknowledges support from William Paterson University's Cannabis Research Institute. The content is solely the responsibility of the authors and does not necessarily represent the official views of any funders. The views expressed herein are those of the authors and do not necessarily reflect the views of the National Bureau of Economic Research.

NBER working papers are circulated for discussion and comment purposes. They have not been peer-reviewed or been subject to the review by the NBER Board of Directors that accompanies official NBER publications.

(C) 2021 by Rahi Abouk, Charles J. Courtemanche, Dhaval M. Dave, Bo Feng, Abigail S. Friedman, Johanna Catherine Maclean, Michael F. Pesko, Joseph J. Sabia, and Samuel Safford. All rights reserved. Short sections of text, not to exceed two paragraphs, may be quoted without explicit permission provided that full credit, including $\odot$ notice, is given to the source. 
Intended and Unintended Effects of E-cigarette Taxes on Youth Tobacco Use

Rahi Abouk, Charles J. Courtemanche, Dhaval M. Dave, Bo Feng, Abigail S. Friedman, Johanna Catherine Maclean, Michael F. Pesko, Joseph J. Sabia, and Samuel Safford

NBER Working Paper No. 29216

September 2021, Revised October 2022

JEL No. H2,I1,I18

\section{ABSTRACT}

Over the past decade, rising youth use of e-cigarettes and other electronic nicotine delivery systems (ENDS) has contributed to aggressive regulation by state and local governments. Between 2010 and mid-2019, ten states and two large counties adopted ENDS taxes. We use two large national surveys (Monitoring the Future and the Youth Risk Behavior Surveillance System) to estimate the impact of ENDS taxes on youth tobacco use. We find that ENDS taxes reduce youth ENDS consumption, with estimated ENDS tax elasticities of -0.06 to -0.21 . However, we estimate sizable positive cigarette cross-tax effects, suggesting economic substitution between cigarettes and ENDS for youth. These substitution effects are particularly large for frequent cigarette smoking. We conclude that the unintended effects of ENDS taxation may considerably undercut or even outweigh any public health gains.

Rahi Abouk

William Paterson University

Department of Economics, Finance, and Global Business

300 Pompton Road

Wayne, NJ 07470

aboukr@wpunj.edu

Charles J. Courtemanche

Department of Economics

Gatton College of Business and Economics

University of Kentucky

Lexington, KY 40506-0034

and NBER

courtemanche@uky.edu

Dhaval M. Dave

Bentley University

Department of Economics

175 Forest Street, AAC 195

Waltham, MA 02452-4705

and IZA

and also NBER

ddave@bentley.edu
Bo Feng

American Institutes for Research

10420 Little Patuxent Parkway

Suite 300

Columbia, MD 21044

bfeng@air.org

Abigail S. Friedman

Department of Health Policy \& Management

Yale School of Public Health

Yale University

60 College St, Rm. 303

New Haven, CT 06520-8034

abigail.friedman@yale.edu

Johanna Catherine Maclean

Schar School of Policy and Government

George Mason University

Mason Square

Van Metre Hall

3351 Fairfax Drive

Arlington, VA 22201

and NBER

jmaclea@gmu.edu 
Michael F. Pesko

Department of Economics

Andrew Young School of Policy Studies

PO Box 3992

Atlanta, GA 30302-3992

and IZA

mpesko@gsu.edu

Joseph J. Sabia

San Diego State University

Department of Economics

Center for Health Economics

\& Policy Studies

5500 Campanile Drive

San Diego, CA 92182

and IZA \& ESSPRI

jsabia@sdsu.edu

Samuel Safford

Michigan State University

Department of Sociology Center for Health Economics

\& Policy Studies (CHEPS) 509 East Circle Dr

East Lansing, MI 48824

safford5@msu.edu 


\section{Introduction}

In 2009, public health officials in the United States established Healthy People 2020 goals, one of which was to reduce the youth smoking rate from $19.5 \%$ to $16.0 \%$ by 2019 (HealthyPeople.gov 2020). In the introduction to a 2012 Surgeon General report on smoking, Department of Health and Human Services Secretary Kathleen Sebelius warned that “...youth and adult smoking rates that had been dropping for many years have stalled” (US Department of Health Human Services 2012). This situation quickly changed, however, as youth smoking rates fell to $6.0 \%$ by 2019, thus surpassing the Healthy People 2020 objective by 386\%. What caused such an unanticipated decline in youth cigarette smoking? ${ }^{1}$ One candidate is the introduction of electronic cigarettes and other electronic nicotine delivery systems (“ENDS”). ENDS were first imported into the US in August 2006 (CASAA 2020) and overtook cigarettes as the most commonly used tobacco product among youth in 2014 (Pesko and Warman 2021). In 2019, 32.9\% of youth used an ENDS over the past 30 days, while 10.7\% used ENDS frequently; that is, on 20 or more of the past 30 days (Centers for Disease Control and Prevention 2020).

On the whole, the current scientific consensus is that ENDS are likely substantially less dangerous than combustible tobacco products (e.g., cigarettes), which are estimated to kill 480,000 Americans annually (US Surgeon General 2014). However, the exact relative risks remain uncertain. Based on data from an August 2020 survey of 137 tobacco scholars, the mean (median) tobacco expert believed that the effect of vaping ENDS on quality-adjusted life expectancy was 37\% (25\%) as large as the effect of smoking (Allcott and Rafkin 2021). Accounting for harms to others as well as the user, a 2013 expert panel concluded that ENDS were unlikely to exceed 5\% of the harm of cigarettes (Nutt et al. 2014), a statistic cited in subsequent reviews of evidence on ENDS’ effects sponsored by Public Health England (McNeill et al. 2018). While the US debate does not use a specific estimate for these products' relative risks, the National Academies of Sciences, Engineering, and Medicine’s 2018 report concluded that “...e-cigarettes appear to pose less risk to an individual than combustible tobacco cigarettes"

\footnotetext{
${ }^{1}$ Some data sources, such as the National Youth Tobacco Survey, show an acceleration in youth cigarette use reductions starting in 2012 (Meza, Jimenez-Mendoza, and Levy 2020), but this acceleration is not obvious in other data sources. However, assuming that demand curves are convex in the left and/or straight or concave in the middle, cigarette regulation would yield less impact in terms of reducing smoking from lower levels of use than higher levels of use. Therefore, the continuation of smoking reductions even through low levels of youth cigarette use as seen recently could suggest ENDS introduction has an impact larger than is immediately obvious from observing consistent youth smoking declines.
} 
and “...e-cigarette aerosol contains fewer numbers and lower levels of toxicants than smoke from combustible tobacco cigarettes.” Health costs may be higher, however, for informally sourced ENDS products than mainstream commercial ENDS because of unknown additives.

ENDS may affect youth health differently than adult health. One commonly cited reason is the potential deleterious effects of nicotine on youth brain development. However, as this evidence is based mostly on studies of rodents (US Surgeon General 2016), the relationship's generalizability to humans is unclear (Balfour et al. 2021). Similarly, the magnitude of the danger posed by nicotine compared to other substances like alcohol, tetrahydrocannabinol (THC), caffeine, and sugar on adolescent brain development is also unclear.

Another commonly-voiced concern is the 2016 Surgeon General report's conclusion that “...e-cigarette use is strongly associated with combustible tobacco product use” (US Surgeon General 2016). However, the idea that this association reflects a causal effect of ENDS use on subsequent smoking is inconsistent with the typical directionality of uptake over time-daily smoking is more common among young adults who tried cigarettes before ENDS (Friedman, Buckell, and Sindelar 2019; Etter 2018). This stated association also fails to accurately forecast rapidly declining youth cigarette use. Despite causal evidence that reducing ENDS access increases youth smoking (Pesko 2022b), the Surgeon General has declared high rates of youth ENDS use to be an epidemic (US Surgeon General 2018).

Policies designed to reduce access to ENDS therefore appear to prioritize the goal of reducing nicotine use-nicotine which has limited adverse effects on health outside of causing addiction-over the goal of harm reduction, which recognizes substitution from higher to lowerrisk nicotine products by people who would not otherwise be able to quit as a benefit for public health. Such regulations have been increasing over time, beginning with ENDS minimum legal sales ages of 18 or higher implemented in all states between 2010 and 2016. As of March 2021, 30 states had adopted ENDS taxes (Public Health Law Center 2022) while 23 had added ENDS to their existing indoor smoking laws (American Non-Smokers Rights Foundation 2021).

Despite significant interest in the effect of regulation on youth ENDS use, studies have not yet estimated the effect of ENDS taxes on youth ENDS and combustible tobacco product use. We explore this question using two nationally representative datasets: Monitoring the Future (MTF) and the Youth Risk Behavior Surveillance System (YRBSS). Specifically, we use a 
continuous treatment difference-in-differences research design to estimate the relationship between ENDS taxes and a variety of outcomes, including ENDS use, combustible tobacco product use, sources of ENDS products (e.g., online purchasing, brick-and-mortar retailers, social sources), and perceived risk of ENDS use. In both MTF and YRBSS, we find that ENDS taxes reduce youth ENDS use and raise youth cigarette use, with evidence of particularly large effects on using these products regularly. We also find evidence that ENDS taxes raise perceptions of ENDS risk and shift the manner that youth obtain ENDS from retail sources to social sources.

By documenting both intended and unintended effects of ENDS taxation on youths, this study's findings contribute to determining optimal ENDS tax policy. In particular, our results speak directly to the question of whether ENDS accessibility reduces youth combustible tobacco use. If this indirect effect on youth tobacco use is positive and large, and the direct harms of ENDS use are small, then imposing large taxes on ENDS products could conceivably worsen public health on net.

\section{Background and related literature}

\subsection{ENDS taxation literature}

There is a nascent but growing economic literature studying the effect of ENDS taxes on vaping and smoking outcomes. Broadly, the available literature suggests that ENDS and cigarettes are economic substitutes, ${ }^{2}$ although the magnitude of this relationship may vary across populations. This finding of substitution is consistent with literature finding minimum legal sales ages for ENDS reduce youth ENDS use (Nguyen 2020; Dave, Feng, and Pesko 2019; Abouk and Adams 2017; Pesko 2022a) and increase youth smoking (Friedman 2015; Pesko et al. 2016; Pesko and Currie 2019; Dave, Feng, and Pesko 2019; Pesko 2022a). A substitution relationship between cigarettes and ENDS is concerning for policymakers as, if true, restricting access to one good may increase demand for the other. Below, we review existing studies on ENDS taxes and tobacco use, and highlight our contributions to this literature. This section also provides evidence

\footnotetext{
${ }^{2}$ One key exception is that Abouk and Adams (2017) find that minimum legal sales ages for ENDS reduces cigarette use among senior high school students, suggesting a complementary relationship between ENDS and cigarettes for this particular population group.
} 
that ENDS accessibility, proxied by the price of the product, has a public health benefit in reducing combustible tobacco use.

Overall population: Using Nielsen Retail Scanner Data (NRSD) from 2011 to 2019, Cotti et al. (2022) show that a $\$ 1.00$ increase in the ENDS tax reduces ENDS sales by $52 \%$ and increases cigarette sales by $10 \%$, which translates to an ENDS own-tax elasticity of -0.63 and cross-tax elasticity of 0.12. Cigarette taxes meanwhile have an own- [cross-] tax elasticity of -0.24 [0.83]. Allcott and Rafkin (2021) also use Nielsen data within the context of a broader shift-share paper, finding some evidence of substitution depending on whether area-specific time trends are included in the regression model or not.

Adults: Pesko, Courtemanche, and Maclean (2020) use 2011-2018 data from the Behavioral Risk Factor Surveillance Survey and the National Health Interview Survey to study the effects of ENDS and cigarette taxes on adult vaping and smoking. The authors find that a $\$ 1.00$ increase in the ENDS tax rate increases adult daily smoking propensity by $5.3 \%$ and the probability of "dual use” (i.e., consuming both ENDS and cigarettes) by 24.4\%. These findings suggest a daily ENDS own-tax elasticity of -0.109 and cross-tax elasticity of 0.041 . Further, cigarette taxes have an own- [cross-] tax elasticity on daily use of -0.085 [0.218] (Pesko, Courtemanche, and Maclean 2020).

Considering the experience of Minnesota, which adopted the first in the nation ENDS tax in August 2010, Saffer et al. (2020) test the effect of ENDS taxation on adult smoking. Using synthetic control methods, the authors find that adult smoking increases following an ENDS tax hike. The results imply a cross-elasticity of current smoking participation with respect to ENDS taxes of 0.13 .

Friedman and Pesko (2022) study the effect of ENDS taxes on young adults ages 18-25 using data from the Current Population Survey’s Tobacco Use Supplement. They find that young adults use ENDS and cigarettes nearly interchangeably, with an ENDS own- [cross-] current 
(past 30-day) use tax elasticity of -0.539 [0.229] and a cigarette own- [cross-] current use tax elasticity of $-0.429[1.205]^{3}$

Pregnant women: Abouk et al. (2022) study the effects of state and local ENDS taxes on pregnant women's smoking behaviors. The authors use national birth record data of mother's conceiving between 2013 to 2019 and investigate the effect of ENDS taxes on pre-pregnancy smoking and prenatal smoking. They find that raising ENDS taxes by $\$ 1.00$ increases prepregnancy smoking by 0.5 and prenatal smoking by 0.4 percentage points (pp), which translates to a cross-tax elasticity of approximately 0.06. Using data from the Pregnancy Risk Assessment Monitoring System, the authors also find that ENDS taxes reduce pre-pregnancy ENDS use by 1.8 pp (elasticity $=-0.28$ ). The authors also find evidence that ENDS taxes increase news coverage of ENDS and raise perceptions of risk of ENDS.

Youth: Pesko and Warman (2021) examine the effect of Minnesota's 2013 ENDS tax increasethat is, above the tax level when first adopted in 2010 — on youth smoking. The authors find that a $100 \%$ ad valorem tax increases cigarettes smoked among youth (unconditional on smoking status) by five additional cigarettes per month, or a little over three packs monthly for smokers using the mean youth smoking rate of 7.9\%. Anderson, Matsuzawa, and Sabia (2020) primarily study the effect of cigarette taxes on youth marijuana use, but include an extension to the main analysis estimating the effect of ENDS tax adoption in three states (California, Pennsylvania, and West Virginia) using two waves of YRBSS data (2015 and 2017), one of the datasets we employ. Their empirical models include an indicator variable for ENDS taxes, implicitly treating all taxes equivalently regardless of their size and ignoring later changes in state ENDS tax rates. They find that ENDS tax adoption reduces current ENDS use by 3.4 pp and daily ENDS use by 0.8 pp, with imprecisely estimated effects on cigarette use.

\footnotetext{
${ }^{3}$ Elasticities are estimated based on our own calculations.
} 
To further our understanding of how ENDS taxes impact youth vaping and smoking, we build on these two studies in several ways. First, we leverage variation in ENDS taxes generated by ten states and two counties rather than a single state (Pesko and Warman 2021) or three states (Anderson, Matsuzawa, and Sabia 2020). Second, we quantify and exploit heterogeneity in ENDS tax magnitudes. These tax sizes vary substantially, from $\$ 0.05$ per fluid milliliter (ml) in Delaware, Kansas, Louisiana, and North Carolina to over a \$1.00 per fluid ml in California, Cook County Illinois, Minnesota, Pennsylvania, and Washington DC. Considering these differences allows us to report our findings in standard tax-elasticity terms and informs policy discussions by quantifying effects on youth tobacco product use for a specific tax policy. Third, we explore ENDS tax effects on how youth obtain ENDS. Given evidence that the 2019 outbreak of vaping-associated lung injuries was driven by additives in informally-sourced vaping products, shifts in youth product sourcing-e.g., from licensed retailers to informal contacts who may mix their own vaping concentrates outside of a retail setting like a vape shop-could have substantive health implications. Fourth, we consider a range of tobacco products that are common among youth but are taxed less aggressively (e.g., cigars), allowing us to characterize multiple margins along which youth may respond to ENDS taxes.

\section{Data and methods}

\subsection{Data}

Our analyses match policy data to two survey datasets, each of which has complementary strengths: the annual MTF dataset and the biennial YRBSS. Restricted-use, annual MTF data cover a nationally representative sample of $8^{\text {th }}$-, $10^{\text {th }}$-, and $12^{\text {th }}$-grade students in middle and high schools in the contiguous US, interviewing about 45,000 youth from nearly 400 public and private schools in the spring of each year. Our main analytic sample is comprised of MTF data for 2014 - the first wave to include questions about ENDS use - through 2019, to avoid disruption from the COVID-19 outbreak starting in 2020. For cigarette use outcomes, sensitivity analyses extend the sample back to 2011. Restricted-use MTF data allow us to identify the county where each respondent's school is located, in order to match respondents to their tobacco policy exposure at the county level. 
The MTF survey includes several questions about cigarette and ENDS use and perceived risk of regular ENDS use. We use different questions to create the following variables, as described in detail in the Online Data Appendix: current ENDS use, ${ }^{4}$ frequent ENDS use (20 or more days over the past 30 days), ENDS initiation during the school year, ever ENDS use, current cigarette use, current cigarette or cigar use, current half pack daily cigarette use, and perceived likelihood of regular ENDS use being highly risky. In general, MTF information is collected across six different surveys (forms) each year, with ENDS questions included on a subset of these forms. Consequently, ENDS sample sizes are somewhat smaller than cigarette sample sizes. Ever ENDS use and ENDS initiation in particular were not collected in 2014 and only on select forms thereafter. For some years, some small states do not have any schools participating in the MTF survey. We restrict our main MTF analyses to a sample of states surveyed in each year to reduce sampling variability, which causes six small states to fall out of regression analysis, including two with ENDS taxes. ${ }^{5}$ Reassuringly, we show in a sensitivity analysis that our results also hold when inconsistently collected states are retained.

The National and State YRBSS survey high school students in public and private schools across the US about their health behaviors biennially. The Centers for Disease Control and Prevention (CDC) administer the National YRBSS, while State YRBSS data are collected by state education and health departments under CDC supervision, using a similar survey instrument. As YRBSS first asked about ENDS use in 2015, our analytic sample is limited to 2015-2019. Pooling the National and State datasets provides greater statistical power due to an increased sample size $(\mathrm{N}>580,000)$, and ensures that all states that adopted an ENDS tax by the end of June 2019 are represented.

YRBSS asks about ever use and frequency of past 30-day use for cigarettes, "electronic vapor product[s]” followed by example brand names marketed as nicotine ENDS (e.g., JUUL,

\footnotetext{
${ }^{4}$ Since 2017, MTF has asked respondents more detailed questions about ENDS use, including questions on whether respondents "vape" nicotine, marijuana, or flavoring. For these years, we consider vaping nicotine as ENDS use, but not vaping marijuana. This general change in the wording of the ENDS-related questions will be captured in the models by the period fixed-effects. We also show later (Appendix Table 8) that redefining our outcome as "any vaping" to be consistent with the pre-2017 questionnaire wording and ignoring the detail provided from the post2017 change, has very little effect on the main estimates.

${ }^{5}$ MTF disclosure rules prevent naming specific states.
} 
Vuse, blu), ${ }^{6}$ and “cigars, cigarillos, or little cigars," as well as how respondents usually obtain ENDS products. Additionally, the final two surveys also collected information on source of ENDS (i.e., retail, internet, social, other). While National and State YRBSS identify the state where a respondents' school is located, they do not provide county or other substate identifiers. ${ }^{7}$

We weight both the MTF and the state and national YRBSS to return nationally representative results. To construct weights, we use the National Cancer Institute's Surveillance, Epidemiology and End Results Program (SEER) data to calculate the state-by-year share of the youth population that falls in each age-by-gender-by-race/ethnicity bin $i$, sist (age 14, age 15, age 16, age 17, age 18, male, female, non-Hispanic White, non-Hispanic Black, Hispanic, and other race/ethnicity). We then calculate each respondent's sample weight as $\left[\mathrm{s}_{i s t} / \mathrm{n}_{\text {ist }}\right]$ *StatePop14_18st, where $\mathrm{n}_{\text {ist }}$ is the number of YRBSS sampled individuals in age-by-gender-by-race-ethnicity bin $i$ in state $s$ at year $t$ and StatePop14_18st is the SEER estimated population of 14-to-18-year-olds in state $s$ at year $t$. In this construction, we are following the recent literature that applies similar SEER-constructed weights in analyses of the combined YRBSS data (Rees, Sabia, and Kumpas (2020); Bryan et al. (2020); and Sabia and Anderson (2016)). We use the SEER-constructed weights to accommodate the multi-year and multi-grade MTF analysis, and to maintain consistency with the YRBSS analysis. Sensitivity analyses show that our results are similar when using unweighted data.

We match tobacco control and other related policy data from public and proprietary sources to respondents by county for MTF and by state for YRBSS, since the latter lacks substate identifiers. We match these policy data by quarter for MTF and by year for YRBSS, since YRBSS does not include month or quarter of interview information. In particular, we average values across the $1^{\text {st }}$ and $2^{\text {nd }}$ quarters of each YRBSS survey year to match when the survey is typically fielded. Policy variables include cigarette excise taxes (the summation of federal, state, and local), percent population covered by indoor smoking restrictions and indoor vaping restrictions (two separate variables) in bars, restaurants, and private workplaces (each venue weighted equally), state laws establishing minimum legal sale ages for ENDS (0/1), percent

\footnotetext{
${ }^{6}$ Please see the Online Data Appendix for question prompts and wording.

${ }^{7}$ To account for sub-state ENDS taxes in Illinois and Maryland, we construct a population-weighted tax value (e.g., for Illinois, we construct a weighted average between Cook County, which has a tax, and the rest of the state, which has not tax, where the weights are populations).
} 
population covered by Tobacco 21, laws prohibiting smoking and vaping in K-12 public schools (two separate variables, 0/1), ENDS product packaging laws (0/1), ENDS retail licensure requirements (0/1), beer taxes, vertical ID laws (0/1), medical marijuana legalization (0/1), recreational marijuana legalization (0/1), unemployment rates, and poverty rates. See the Online Data Appendix for further information and sources. All local laws are population-weighted to the county level for MTF and to the state level for YRBSS. All monetary variables are adjusted to 2019 dollars using the Bureau of Labor Statistics’ Consumer Price Index.

Our main policy variable of interest is the state or local ENDS tax rate. ENDS taxes are levied in different ways, including as an excise tax per unit or fluid ml of liquid, or as an ad valorem tax on wholesale prices. Cotti et al. 2021 developed a method to standardize these taxes into a single ENDS tax per fluid ml measure as shown in Table 1. In brief, the authors used 2013 to identify an average national ${ }^{8}$ wholesale price of $\$ 2.63$ per fluid $\mathrm{ml}$ and 1.02 containers per fluid ml, and then multiplied future tax changes by these base values to generate taxes standardized per fluid ml. One benefit of this measure is that only legislated tax changes affect standardized tax values, thus avoiding endogeneity of prices and related issues (Gruber and Köszegi 2001). For reference, one JUUL pod has 0.7 fluid ml, equivalent to approximately one pack of cigarettes (Truth Initiative 2019). ${ }^{9}$

Table 2 reports MTF and YRBSS descriptive statistics with weights for the variables discussed above, separately for the overall sample and two sub-samples: areas that implemented ENDS taxes by the end of 2019 and areas that did not. Current ENDS use rates are 15.2\% in MTF and 21.1\% in YRBSS, with mean rates approximately 1.5 pp higher in non-treated than treated states. Current cigarette use rates are approximately $6.6 \%$ in the MTF and $8.1 \%$ in the YRBSS, and are also moderately higher in non-treated states. YRBSS results may report higher

\footnotetext{
${ }^{8}$ Cotti et al. 2021 find evidence that ENDS companies use national pricing strategies based on an examination of retail prices over time for the three most common products sold in twenty tax jurisdictions that did not adopt ENDS taxes through the end of 2020. This supports the use of a single base wholesale price and estimate of containers per fluid ml.

${ }^{9}$ Between 2014 and 2019, the correlation between population-weighted state-level, quarterly ENDS taxes and cigarette taxes was 0.304. In a regression model with ENDS taxes as the dependent variable and controlling for cigarette taxes, fixed effects, and other time-varying and demographic controls, the $\mathrm{R}^{2}$ is 0.916 from $2015-19$ for YRBSS and 0.872 from 2014-19 for MTF. Taken together, these results suggest significant independent identifying variation remains in both ENDS and cigarette taxes.
} 
ENDS use in part because YRBSS only includes high school students, whereas MTF also includes $8^{\text {th }}$ graders, who are less likely to use these products.

Non-adopting states appear to have higher shares of White, non-Hispanic youth, and less restrictive tobacco control regulation generally, though higher beer taxes and less marijuana access. Unweighted descriptive results are provided in Appendix Table 1.

\subsection{Methods}

To investigate the effect of ENDS taxes on youth vaping and smoking outcomes, we estimate the following regression model for county-level MTF data:

$$
\text { (1) } Y_{i l t}=\alpha+\gamma_{l}+\delta_{t}+\beta_{1} E N D S \operatorname{tax}_{l t}+\boldsymbol{X}_{i t} \boldsymbol{\beta}_{\mathbf{2}}+\boldsymbol{Z}_{c t} \boldsymbol{\beta}_{\mathbf{3}}+\varepsilon_{i l t} \text {, }
$$

The parameter $\beta_{1}$ is the coefficient of interest, which captures the effect of ENDS taxes on our outcomes. $\boldsymbol{X}_{\boldsymbol{i}}$ is a covariate matrix comprised of individual-level sociodemographic variables (gender, age, grade, and race/ethnicity [White, Black, Hispanic, and other], along with missingvalue indicators for each sociodemographic variable). $\boldsymbol{Z}_{\boldsymbol{c} t}$ adjusts for the policies described above.

Distinct analyses will consider each of the following outcomes as $Y_{i l t}$ : any ENDS use in the past 30 days, frequent ENDS use (20 or more days over the past 30 days), initiating ENDS use during the current school year, current cigarette use, various measures of heavy cigarette use, current cigarette or cigar use, perceived likelihood of regular ENDS use being highly risky, and source of ENDS (i.e., retail, internet, social, other).

The above specification is based on a continuous treatment difference-in-differences research design, capitalizing on the variation in treatment intensity generated from jurisdictions newly adopting ENDS taxes of varying amounts as well as subsequent changes to their tax rates. The specification includes "two-way fixed effects” (TWFE) to account for spatial and temporal heterogeneity. Fixed-effects for year-quarter of interview $\left(\delta_{t}\right)$ adjust for national time trends, while area (or jurisdiction) fixed-effects $\left(\gamma_{l}\right)$ adjust for time-invariant differences in the outcome variable by tax jurisdiction $l$, defined here as states with two exceptions: Cook County, Illinois 
and Montgomery County, Maryland, both of which are separated from their respective states due to local ENDS taxes, as in other work (Cotti et al. 2022; Allcott and Rafkin 2021).

As YRBSS data lack interview quarter and county identifiers, those analyses utilize state and year rather than tax jurisdiction and quarter. Otherwise, the MTF and YRBSS specifications are identical. Standard errors are clustered by state for both data sources.

\section{Results}

\subsection{Effects of ENDS taxes on ENDS outcomes}

Table 3 panel A presents estimates of the standardized ENDS tax rate's effects on youth ENDS use. The first four columns' specifications leverage the MTF's ENDS data availability to estimate responses along various consumption margins. Coefficient estimates generally suggest that higher ENDS taxes are effective in reducing use among youth, with marginally statistically significant reductions (10\% level) in current and regular ENDS use, and a statistically significant decline in ever-use. Specifically, a \$1.00 increase in the standardized tax, which represents about twice the observed standard deviation in the tax, reduces the likelihood of currently using ENDS by $1.9 \mathrm{pp}$ (model 1). The estimated ENDS participation tax elasticity is -0.08 , which translates into an ENDS participation price elasticity of -0.43 for the youth population. ${ }^{10,11}$

The ENDS participation margin here combines regular users and occasional users. About three quarters of adolescents who report currently using ENDS do so occasionally and are not regular users (see Table 2). When we expressly consider whether higher ENDS taxes impact those who use ENDS more frequently, we continue to find a marginally significant negative effect. Comparing the coefficient estimates between current use and regular use indicates that

\footnotetext{
10 The elasticity is estimated based on the mean tax rate and ENDS outcome for the treated units. In other words, $\varepsilon=$ $\beta \cdot \mathbb{E}(\mathrm{x}) / \mathbb{E}(\mathrm{y})$, where $\mathbb{E}(\mathrm{x})$ and $\mathbb{E}(\mathrm{y})$ are calculated using data points from the treated units over the sample period. We use the treated units for this calculation for two reasons. First, note that $\mathbb{E}(\mathrm{x})$ is by definition zero for the non-treated units. Second, this measure of the elasticity captures the average treatment effect on the treated (ATT), summarizing what would have happened to the tobacco use outcomes in the treated states in the absence of the treatment.

11 The price elasticity can be derived from the tax elasticity as follows: $\varepsilon_{\text {Price }}=\varepsilon_{\text {Tax }} *$ (1/tax pass-through) $*(1 /$ share of tax in the price). Cotti et al. 2022 estimate that ENDS taxes are almost fully passed on to retail prices (0.9 passthrough rate), and comprise about $21 \%$ of the observed retail price. If the tax pass-through is larger than one, which is possible under monopsony market conditions or perfect competition with feedback loops between related goods, then the implied price elasticity would be lower in magnitude. For instance, if the tax pass-through is 1.33 (see Saffer et al. 2020), then the implied ENDS price-participation elasticity would be -0.35 .
} 
about two-thirds of the reduction in current use associated with higher ENDS taxes is driven by a reduction in regular use (1.3/1.9 pp), suggesting that this latter, more intense, margin of use is especially elastic. This pattern is borne out by the estimated tax elasticity of regular use, which is more than double the participation elasticity (-0.21 vs. -0.08$)$.

Among adolescents in particular, current ENDS use includes established users, new initiates, and experimenters. Column (3)'s results suggest that higher ENDS taxes may deter initiation, with the tax elasticity (-0.06) similar to that for ENDS participation (-0.08), though imprecisely estimated. As our initiation measure is noisy, potentially explaining this imprecision, we turn to ever-use of ENDS - which is directly reported in the data - as a proxy for initiation and experimentation (Dave et al. 2019). By definition, year-to-year changes in ever-use — the variation leveraged in fixed-effects models - capture the prevalence of new initiates and experimenters. Thus, taxes' effects on ever-use should reflect their impacts on new initiation and experimentation. We find a significant and relatively large effect of ENDS taxes on ever-use of ENDS, with a \$1.00 increase in the standardized tax resulting in a 5.2 pp decrease in ever ENDS use.

Reassuringly, the last column in Table 3 Panel A confirms that higher taxes significantly and effectively reduce current ENDS use in a different adolescent sample (YRBSS). That coefficient estimate is larger than the MTF estimate, perhaps due in part to higher mean ENDS use in the YRBSS, which started collecting ENDS data one year later than MTF and considered older respondents (high school students only).

Estimates of the cross-effects of cigarette taxes on ENDS use are generally insignificant, in line with recent evidence that cigarette taxes may have lost their bite in terms of affecting youth (Hansen et al. 2017). Only for regular ENDS use is there a marginally significant effect of cigarette taxes, suggesting that higher cigarette taxes may drive some adolescents to substitute towards frequent ENDS use, consistent with the products being economic substitutes for youth.

Table 3 panel B reports estimates for other outcomes related to ENDS use, including perceived risk (from the MTF) and source of ENDS purchases (from the YRBSS). Column (1) suggests that higher ENDS taxes significantly increase the perceived risk of using that product among youth, which is similar to previously reported findings for reproductive age women (Abouk et al. 2022). While stricter tax policy might lead adolescents to adjust their risk beliefs 
directly, perhaps by reducing the general availability of ENDS and drying up the social market, an alternative explanation is that risk beliefs are concurrent to (or bundled with) individuals' consumption decisions. For instance, Viscusi (2016) finds that cigarette users expect ENDS to be less risky than non-users. In this context, the reduction in ENDS use and initiation (Table 3 panel A) and the upward adjustment of the perceived risk of ENDS use would go hand-in-hand.

Given that retailers are restricted from selling ENDS to youth (by federal law since August 2016 and in most states even earlier than that), the finding that youth are responding to the monetary cost of a product that they are legally restricted from purchasing may appear counterintuitive. ${ }^{12}$ However, as shown in Table 2, a sizeable fraction (25\%) of adolescents who use ENDS report purchasing the product themselves either through retail or internet sources. These individuals would be directly affected by any increase in the monetary cost. Others who obtain ENDS through social sources or third-party purchases may also be affected (e.g., if price increases are passed on via the third party or affect peers’ willingness to share). ${ }^{13}$

As expected, retail purchases by youth are the most responsive to higher ENDS taxes (see Table 3 Panel B). A \$1.00 increase in ENDS taxes reduces the likelihood that youth obtain their ENDS through retail sources by about 7.6 pp (41.1\% relative to the sample mean). Moreover, we also find a significant reduction in "other sources” (e.g., stealing from a store). These findings are consistent with Table 3's coefficient estimates, corroborating the hypothesis that higher taxes decrease youth ENDS consumption primarily through retail purchases. Moreover, the indication that higher taxes may shift how teens acquire ENDS is notable. Specifically, among those who continue to use ENDS, there is evidence of substitution away from retail and other sources into social sources (10.1 pp or $16.1 \%$ increase), a shift which may have direct adverse health effects if socially-sourced ENDS products are more likely to be contaminated with unknown additives. Critically, higher cigarette taxes, which lower the relative cost of ENDS, appear to have inverse effects, encouraging significant substitution towards retail ENDS purchases and away from the social market.

\footnotetext{
12 All models control for minimum legal sales age restrictions for ENDS.

${ }^{13}$ In the case of cigarettes, youth acquisition in the social market has generally not been found to be responsive to cost, though higher cigarette taxes do reduce the likelihood of youth obtaining their cigarettes through third-party purchases (Katzman, Markowitz, and McGeary 2007; Hansen, Rees, and Sabia 2013).
} 


\subsection{Effects of ENDS taxes on cigarettes and other tobacco product use}

While higher ENDS taxes appear to significantly deter youth from using ENDS, the public health implications of this impact depend on potential substitution towards other higherrisk tobacco products. We assess this possibility with the results reported in Table 3 panel C, considering reported use of combustible tobacco products (cigarettes and cigars) from MTF (columns 1-3) and YRBSS (columns 4-7). Coefficient estimates based on the MTF sample suggest that higher ENDS taxes significantly increase cigarette use, on both the extensive and intensive margins. Consumption of at least a half pack per day is particularly responsive to shifts in ENDS tax policy, with a $\$ 1.00$ increase in the standardized ENDS tax increasing it by $1.3 \mathrm{pp}$. YRBSS sample estimates suggest a similar pattern of substitution into cigarette use from higher ENDS taxes, with coefficient estimates largely similar to the MTF estimates though imprecise due to inflated standard errors. Across outcomes, own-effects of cigarette taxes are negative but not statistically distinguishable from zero. ${ }^{14}$

If ENDS taxes impact the demand for other tobacco products only through their direct effects on the demand for ENDS, the own-tax effects on ENDS use in Table 3 can be construed as a "first-stage" effect, bounding the size of the impacted adolescent population that may substitute towards other tobacco products. Specifically, MTF estimates suggest that a $\$ 1.00$ increase in the ENDS tax reduces ENDS participation by about $2.0 \mathrm{pp}$. We would therefore not expect the spillover effects of ENDS taxes on cigarettes to be larger than this magnitude. About 2\% of adolescents (based on the MTF) are changing their ENDS use behaviors due to higher ENDS taxation, and a subset of these (1.3 pp or about $68 \%$ of the impacted population) are switching to cigarettes. This "treatment-on-the-treated" effect is smaller if we use the YRBSS estimates, which suggest that 23\% of teens who respond to higher ENDS taxes with reduced ENDS use are substituting towards regular cigarette use. Such scaled estimates should be interpreted with caution, and are meant to be suggestive, since they can vary dramatically with

\footnotetext{
14 This pattern of relatively low youth cigarette tax responsiveness is in line with other recent studies (Hansen, Sabia, and Rees 2017). The insignificant own-tax effects and significant cross-tax effects may reflect that tax evasion methods are likely mature and sophisticated by this point for cigarettes, but not yet well-developed for ENDS (due to the relatively low ENDS tax rates and relative recent emergence of ENDS more generally). Given the focus on youth, income effects may also be at play. For instance, if cigarettes take up a relatively larger fraction of youths' income, then the lower remaining income (from higher cigarette taxes) may counter the pure price effect if cigarettes are an inferior good.
} 
small changes in the underlying parameters. Nevertheless, they provide a means to gauge the credibility of estimated ENDS tax effect-sizes, and broadly suggest that a non-negligible fraction of teens reducing their use of ENDS because of a tax could be substituting into combustible tobacco use instead.

\subsection{Effects of ENDS taxes on dual-use and any use outcomes}

Across our sample period, approximately 30\% of current (past-month) ENDS users also currently use cigarettes. From a health perspective, “dual-use” could represent a good or bad outcome. Dual-use of ENDS and a combustible tobacco product could be health-improving if it represents attempts to quit and/or reduce cigarette smoking, or health-deteriorating if it facilitates continued smoking among individuals who would otherwise quit (e.g., if they could not continue using nicotine in smoke-free locations). In Table 4, we do not find statistically significant evidence that ENDS taxes affect youth dual-use or for that matter, an indicator for any use (i.e., of ENDS or combustible tobacco).

\subsection{Heterogeneous effects of ENDS taxes}

In Figures 2-5, we assess whether vaping- and smoking-responses to ENDS taxes differ across gender, age, and race for Table 3 outcomes that were statistically significant $(p<0.10)$. These figures summarize estimates from stratified samples, parallel to the pooled-sample coefficient estimates presented in Tables 3. In our discussion of these results, we draw on the weight of the evidence across broad patterns that emerge from these coefficient estimates.

Figures 2 and 3 respectively present heterogeneous responses in ENDS use across subpopulations from the MTF and the YRBSS. The effect of higher ENDS taxes on ENDS use is largely negative for all groups, though some interesting differentials emerge. While ENDS taxes affect male and female ever-use similarly, only females show statistically significant current- and regular-use responses in MTF. The tax effect is also generally larger for older adolescents (ages $16+$ ) than younger adolescents (ages $<16$ ) in both data sources, consistent with more ENDS use 
among older teens. This pattern may also reflect greater reliance on retail sources among older teens, as retail purchases are expected to be more elastic to cost. ${ }^{15}$

When it comes to risk perceptions regarding ENDS, there is some indication that female teens' risk beliefs are more elastic with respect to taxes than males (Figure 4). Differences are even more evident by race: White teens exhibit a much stronger and significant upward revision of their perceived risk of ENDS in response to ENDS taxes, while effects for non-White teens are close to zero and insignificant.

Figure 5 presents differential effects across sources of ENDS acquisition based on the YRBSS. Mirroring the heterogeneity in consumption and use by age, we find that retail purchases (a much more important source of ENDS for older teens and teens that regularly use ENDS) are significantly responsive to taxes for older but not younger adolescents. Similarly, higher ENDS taxes appear to significantly limit younger teens' reliance on the social market, a source which tends to be relatively more important for that age-group. ${ }^{16}$ This relationship may operate as a chain reaction, since many younger teens obtain ENDS by borrowing them from friends or older peers. Specifically, if ENDS taxes constrain older peers' ability to purchase ENDS from retail sources, downstream effects may limit younger teens' ENDS access through social sources. Older teens may respond to ENDS taxes by substituting towards social sources and constraining their own retail purchases, though the substitution here is less than one-to-one. This behavior might be explained if, ex ante, older teens are more likely to pay for their ENDS, while younger teens rely more on "bumming" a vape. In this case, ENDS taxes would have more impact for older teens, and thus larger effects on their current and frequent ENDS use, in line with Figures 2 and 3. Those who substantially reduce their ENDS use in response to taxes may fall back on bumming ENDS from social sources—a habit that might be less socially acceptable or viewed as freeloading for regular or heavy users—instead of purchasing ENDS themselves. ${ }^{17}$

\footnotetext{
${ }^{15}$ According to 2017 and 2019 YRBSS data, 27.7\% of teens ages 16+, who are ENDS users, report obtaining their ENDS via retail sources; in contrast, only 5.5\% of younger ENDS users report that they acquired their ENDS via retail sources. Additionally, only $21.2 \%$ of current ENDS users report retail sources of ENDS, but this rises to $38.7 \%$ and $42.9 \%$ for frequent and daily users.

${ }^{16}$ According to 2017 and 2019 YRBSS data, 74.2\% of ENDS users under age 16 report obtaining ENDS through borrowing from family or friends, a source less commonly reported by older teens (56.6\%).

${ }^{17}$ We also find that older teens may have substituted from retail outlets to internet purchases, potentially allowing some to evade ENDS taxes, particularly prior to the US Supreme Court's June 2018 South Dakota v Wayfair Inc
} 
Finally in Figure 6, we assess heterogeneity in the cross-tax effects on combustible cigarette use for statistically-significant outcomes at baseline. Spillover effects mainly line up with the first-order effects on ENDS use. In particular, older and White teens tend to display a stronger substitution response towards cigarettes than younger and non-White teens.

\section{Checks of validity and robustness}

Table 5, Table 6, and online appendix tables provide additional checks to assess the identifying assumptions' validity and explore our main results' sensitivity to alternate specifications, measurement error in the ENDS tax rate, added observable confounders, and sampling and other estimation issues.

The tax-response parameters are identified off within-state changes over the sample period in the two-way fixed effects regressions, drawing on the assumption of strict exogeneity (Wooldridge 2010). This implicitly presumes that states that have not adopted any ENDS taxes or changed their ENDS tax rates are valid counterfactuals for the "treated" states. More specifically, a consistent estimate of the tax-response parameter ( $\beta_{1}$ in equation 1 ) requires that the tax rate in a given state/locality and period $t$ be orthogonal to that locality's error term in all periods. Violations of this assumption are usually driven by either time-varying state-specific unobservables correlated with the ENDS tax, or policy endogeneity, wherein the state's past experiences with youth ENDS use may influence its enactment and level of ENDS taxation.

The recency of most states' ENDS tax adoption and youth surveys' addition of ENDS use questions prevents estimation of flexible event-study models for ENDS use outcomes. ${ }^{18} \mathrm{We}$ therefore check for potential policy endogeneity and assess the broader identifying assumption by re-estimating models with the inclusion of a one-period lead on ENDS tax adoption (Table 5). ${ }^{19}$ These models underscore two points which instill some degree of confidence in the credibility of the research design. First, coefficient estimates on the lead for ENDS adoption are

decision. Before then, responsibility to pay remote sellers' sales taxes largely fell on consumers, making it difficult to enforce tax collections, including for ENDS. That case's ruling allowed states to require remote sellers to collect these taxes, a policy most states adopted towards the end of 2018 or later; that is, at the end of our period of analysis. ${ }^{18}$ As shown in Table 1, the number of ENDS tax adoptions by year is one in 2010, four in 2015, four in 2016, two in 2017, and one in 2018. ENDS use questions are available annually in MTF starting in year 2014 and bi-annually in YRBSS starting in 2015, thus providing a relatively narrow pre-period for these outcomes.

${ }^{19}$ We exclude ENDS source outcomes since these are only provided in two waves of data. 
statistically insignificant, invariably smaller than the main effect, and largely close to zero in all models. This finding suggests that trends in ENDS use outcomes prior to the adoption of the tax do not materially differ between treated and control states. Second, our main ENDS tax effects on ENDS and cigarette use are not materially altered by controlling for the lead on policy adoption.

In Table 6, we show results using alternative estimation strategies. ${ }^{20}$ First, we show instrumental variables (IV) estimates from models where the standardized tax rate is instrumented with the separate tax components (i.e., ad valorem tax rate, liquid excise tax rate, container excise tax rate). This strategy may reduce any bias due to measurement error in the standardized tax construction. The F-statistic exceeds 10,000, and the IV results are virtually identical to baseline results.

Emerging literature has identified important issues that arise in TWFE analyses with staggered adoption of the treatment, as in our case with multiple jurisdictions shifting their ENDS tax policy at different times. In the presence of dynamic treatment effects, the treatment effect recovered by the TWFE model may be biased and may capture the true treatment effect plus additional terms that reflect deviations from parallel trends and bias due to treatment effect dynamics (Goodman-Bacon 2021). The latter bias is often largely due to using earlier-treated units as a counterfactual for later-treated units.

This issue of heterogenous treatment effect dynamics may be less problematic here than in other contexts given that only nine states plus Washington DC and two large counties imposed taxes on ENDS by mid-2019, when our sample ends. Consequently, we have a large untreated comparison group and, as ENDS taxes are relatively recent phenomena within US markets, few instances of earlier-treated units serving as a counterfactual for later-treated units, minimizing such concerns. This hypothesis is confirmed by a decomposition (Goodman-Bacon 2021) of the comparisons driving the estimated treatment effects in our MTF analyses (dichotomizing our tax variable). This decomposition indicates that between $91.6 \%$ and $94.4 \%$ of the weight of our estimator (depending on outcome) can be attributed to the comparison of treated states (states

\footnotetext{
${ }^{20}$ We estimate these alternative methods using only MTF because YRBSS is otherwise limited by having only three waves of data for e-cigarette use outcomes and by a lack of substate information used in the stacked difference-indifferences model.
} 
that have imposed an ENDS tax) versus never adopters, and between 1.9\% to 3.0\% can be attributed to the comparisons of earlier-adopting versus later-adopting states. The potentially problematic comparison-using earlier-treated or already-treated states as a counterfactual for later-treated states-drives only about $3.7 \%$ to $5.4 \%$ of the average treatment effect in our estimation.

To excise potential impacts from dynamic treatment effects, our first approach is a “stacked difference-in-differences estimator” (Cengiz et al. 2019). For this, we first define a common "event window" around the adoption of an ENDS tax: two years prior to the tax, the year of the tax, and one-year post-tax. ${ }^{21}$ We then define a "cohort" as a collection of treatment tax jurisdictions that experience an “event” at the same time (i.e., jurisdictions that adopt an ENDS tax at the same time). We allow for separate cohorts for tax jurisdictions that adopt the tax in the same period, but have a different “dose” of the event (i.e., ENDS tax level), which allows different doses of the event to have differential impacts. Second, for each cohort, we select tax jurisdictions that have never implemented an ENDS tax by the end of our study period ("never treated”) and those tax jurisdictions that have not yet adopted an ENDS tax during the event window ("not yet treated”) to serve as the comparison group. ${ }^{22}$ By selecting treatment and comparison tax jurisdictions in this manner, we are able to account for two sources of bias in TWFE with a staggered treatment regime: (i) comparing later treated units to earlier treated units which can lead to bias and (potentially) negative weighting if there are dynamic treatment effects across tax jurisdictions (i.e., “forbidden comparisons” (Borusyak, Jaravel, and Spiess 2022)), and (ii) variance weighting which places the most weight on observations whose treatment "turns on" in the middle of the panel (these observations have the greatest variance in treatment status and thus OLS, in minimizing the sum of squared errors, upweights these observations) and may therefore lead to poor estimates of the average treatment on the treated (ATT) effect if there is heterogeneity in the ATT. Finally, we stack each cohort (i.e., collections of treatment tax jurisdictions and each group's comparison tax jurisdictions) and estimate an equation similar to that outlined in Equation (1), but we include cohort-specific tax jurisdiction fixed effects and

\footnotetext{
${ }^{21}$ Since these surveys generally interview youth starting in January of each year and until the school year ends, the "tax year" for the stacked difference-in-differences model is considered to be the first year that the tax was in place by January.

${ }^{22}$ We note that using different comparisons required different assumptions regarding parallel trends. Please see (Marcus and Sant'Anna 2021) for a general discussion of different parallel trends assumptions.
} 
cohort-specific time fixed effects. We continue to cluster standard errors at the tax jurisdictionlevel. For tax jurisdictions that have multiple tax changes, we do not consider later tax changes that occurred outside the event window since these tax jurisdictions are already treated and the effects of later tax changes may be conflated with potential dynamic effects of the earlier tax changes. We also exclude Minnesota as this state was treated throughout our study period.

The middle panel of Table 6 presents estimates of the tax response from this stacked difference-in-differences model. Reassuringly, our previous findings stand: we find consistent and robust evidence that higher ENDS taxes significantly reduce adolescent ENDS use along multiple margins. The stacked difference-in-differences estimates further suggest, as before, that higher ENDS taxes are associated with a greater perceived risk of ENDS and substitution into cigarettes. Coefficient magnitudes of the substitution effects are similar to those from the standard difference-in-differences regression, though only one of three smoking outcomes remains precisely estimated.

Finally, the bottom panel of Table 6 presents results from a recently proposed estimator by de Chaisemartin and d'Haultfoeuille (2022): the multiperiod difference-in-differences (MDID). ${ }^{23}$ Similar to the stacked difference-in-differences estimator outlined above, the MDID estimator produces parameter estimates that are robust to bias from heterogeneous and dynamic treatment effects. MDID is able to accommodate both reversible and multi-valued treatments, which is valuable in our setting. We collapse the data to the tax jurisdiction-year-quarter level using population weights. While MDID can accommodate multi-valued treatments, the estimator cannot accommodate fully continuous treatments such as our ENDS tax variable. Therefore, we re-categorize the continuous ENDS tax into the following bins to create a multi-valued treatment variable: no tax, \$0.01 to \$1.00 tax, \$1.01 to \$2.00 tax, and \$2.01 to \$2.52 (the highest tax amount we observe through mid-2019). We account for within-tax jurisdiction correlations in calculating standard errors. The coefficient estimates show the average effect over the post period for a one unit change in treatment intensity, relative to the period before the ENDS tax comes into place. Coefficient estimates are all in the same direction as our baseline results and sizably larger, though also imprecise. The reduction in precision may be attributable to the MDID estimator being less efficient than OLS, the loss of power from aggregating from the

\footnotetext{
${ }^{23}$ We calculate this estimator using the Stata package -did_multiplegt-.
} 
microdata to the tax jurisdiction-quarter-year level, and conversion from the continuous measure to a multi-valued variable. Please see the Online Methods Appendix for additional discussion of the use of TWFE regression to estimate causal parameters with a continuous treatment variable.

We show that our coefficients are broadly similar to baseline results when modeling the dichotomous outcomes via probit regression (marginal effects are presented in Online Appendix Table 2). ${ }^{24}$ Since source outcomes are mutually exclusive, we also model this using a multinomial logit model in Online Appendix Table 3. We include in this model a category for not using ENDS so as to not condition the sample on only users. Here we find that a $\$ 1.00$ increase in ENDS taxes increases the probability of not using ENDS by 3.1 pp, reduces the probability of purchasing from retail sources by $1.6 \mathrm{pp}$, and reduces the probability of obtaining ENDS from other sources by $1.0 \mathrm{pp}$. There are no statistically significant reductions in obtaining ENDS from social and internet sources, which is consistent with baseline results that are conditional on remaining an ENDS user.

Next, in Online Appendix Tables 4, we show the effect of controlling for alternative sets of variables. ${ }^{25}$ We show our baseline results (from Table 3 ) in the first row. In the second row, we add other state-level tobacco control policies of ENDS licensure laws, ENDS product packaging laws, and K-12 public school campus bans for smoking and vaping products. ${ }^{26}$ The coefficient estimate on ENDS taxes is similar to baseline results when adding the extra controls. In the third and fourth rows, we add little and large cigar tax variables. Each category of cigar has ad valorem and excise taxes depending on the state, and states use different thresholds for determining what constitutes a little cigar; therefore, this lack of standardization makes it difficult to control for these taxes. While results vary somewhat depending on which set of cigar tax variables we control for, across both specifications we collectively find evidence supporting the robustness of all previously reported relationships. Finally, in the last row we control for unique variables available in the MTF: parental education and a respondent's county's

\footnotetext{
${ }^{24}$ Results are also insensitive to using logit.

25 The online data appendix provides a description of the extra policy controls.

${ }^{26}$ We identified these "extra controls" as additional ENDS policies tracked by the Public Health Law Center that we were not previously controlling for (https://www.publichealthlawcenter.org/resources/us-e-cigarette-regulations-50state-review, accessed 10/6/2022) and from a prior ENDS tax paper (Cotti et al. 2022).
} 
urban/rural status. ${ }^{27}$ These controls have no noticeable impact on previously reported relationships.

Next, in Online Appendix Table 5 we show robustness of our results to using alternative samples. In particular, we drop two states that adopted ENDS MLSA and licensure laws at the same time that ENDS taxes came into place, ${ }^{28}$ we retain irregularly surveyed states in the MTF that we otherwise dropped from our main analysis, and we use a longer time horizon (through 2011) for cigarette outcomes.

Finally, we show that our results are consistent when using a broader "any vaping" variable (including of THC) that became available in 2017 (Appendix Table 6) and when not utilizing population weights (Appendix Table 7). In Online Appendix Table 8 we show little in the way of changes in statistical inference when accounting for the small number of treated units through wild cluster bootstrapping, or when accounting for multiple comparisons using HolmBonferroni adjustment ${ }^{29}$ or a sharpened two-stage adjustment (Benjamini, Krieger, and Yekutieli 2006; Anderson 2008).

\section{Discussion}

Our study contributes to the literature by 1) using multiple large-scale youth survey datasets to provide some of the first national evidence of ENDS taxes' effects on youth, and 2) studying the effect of ENDS taxes on youth using four types of outcomes: ENDS use, cigarette use, perceptions of the risk of ENDS, and source of ENDS. By estimating ENDS taxes' effects on youth use of both ENDS and cigarettes, as well as intensity of use, ENDS sources, and ENDS risk perceptions, this research provides the most comprehensive picture to date of ENDS taxes' effects on youth, whom legislators often claim they are protecting when taxing ENDS. While our results yield ENDS tax elasticities ranging from -0.06 to -0.21 depending on the measure of ENDS use, and indicate that ENDS taxes increase perceptions of ENDS risks, other findings suggest concurrent costs: cross-tax elasticities are positive and particularly large for frequent

\footnotetext{
${ }^{27}$ These latter individual-level controls are not available in the YRBSS. We therefore did not include them in our main analyses in order to keep the specifications for the MTF and the YRBSS samples consistent.

${ }^{28}$ MTF disclosure rules prevent naming specific states.

${ }^{29}$ We used three groups of outcomes to adjust for multiple comparisons (ENDS, cigarettes, and depending on data source either ENDS source or risk perception).
} 
cigarette use outcomes, and sourcing results suggest that ENDS taxes shift youth towards social ENDS sources. The latter change may have implications for short- and long-run health outcomes, as observed during the 2019 outbreak of vaping-associated lung injuries, when use of informally sourced cannabis vaping products containing vitamin E acetate led to a rash of illnesses and deaths.

As of March 2022, 30 US states had adopted an ENDS tax (Public Health Law Center 2022). However, if reducing ENDS accessibility increases combustible tobacco use, as suggested by this study and prior work (Pesko, Courtemanche, and Maclean 2020; Saffer et al. 2020; Pesko and Warman 2021; Abouk et al. 2022; Cotti et al. 2022; Friedman 2015; Dave, Feng, and Pesko 2019; M. F. Pesko, Hughes, and Faisal 2016; Pesko and Currie 2019; Friedman and Pesko 2022; Pesko 2022a), these taxes could potentially prove harmful to public health. That is, given current evidence suggesting smoking is substantially more dangerous than using ENDS, the health costs from greater youth smoking as a result of ENDS taxes may considerably undercut or even outweigh benefits from reduced youth ENDS use, though an exact calculation is beyond the scope of this research.

The last version of the Build Back Better (BBB) Act passed by the House of Representatives proposed setting an ENDS tax of \$50.33 per 1,810 milligrams (mg) of nicotine (House Rules Committee 2021). Our MTF results suggest that the equivalent tax per fluid ml in a 5\% JUUL cartridge- - believed to be approximately equivalent to a pack of cigarettes (Truth Initiative 2019)—would reduce youth current ENDS use by 3.0 pp and raise youth current cigarette use by 2.1 pp. ${ }^{30}$ Our YRBSS results suggest reductions in youth current ENDS use of $11.3 \mathrm{pp}$ and increases in youth current cigarette use of $1.3 \mathrm{pp}$. Though substitution rates vary across data sources, our results suggest that unintended effects of the BBB's ENDS tax provision on youth cigarette use may considerably undercut or even outweigh any public health gains of reducing youth ENDS use, assuming that ENDS are less risky products as determined by several government-commissioned reviews (McNeill et al. 2018; National Academies of Sciences, Engineering, and Medicine 2018; UK Committee on Toxicity of Chemicals in Food, Consumer Products and the Environment 2020).

\footnotetext{
${ }^{30}$ JUUL Labs reports each 5\% nicotine concentration cartridge contains approximately 40 milligrams nicotine per pod and has 0.7 fluid $\mathrm{ml}$, so the equivalent tax per fluid $\mathrm{ml}$ is $\$ 1.59$ (40 $\mathrm{mg}$ x [ $\$ 50.33$ / 1,810 mg] / 0.7 fluid ml).
} 
The FDA is currently assessing whether specific ENDS products are sufficiently appropriate for public health to be legally sold in the United States. To date, 23 ENDS products from three companies have been approved, thousands of ENDS products remain under review, and more than one million ENDS have been denied. ${ }^{31}$ Approval can be rescinded at any time if insufficient evidence exists that these products are benefiting public health. ENDS that are under review or were denied marketing orders but those orders are under appeal (such as is the case currently with JUUL ENDS) can be sold through enforcement discretion.

Policy evaluation research is particularly well-suited to assessing ENDS’ overall effect on public health by estimating how reducing the accessibility or appeal of ENDS affects use of more lethal, combustible tobacco products. If reducing ENDS accessibility increases combustible tobacco use, as suggested by this and other studies (Pesko, Courtemanche, and Maclean 2020; Saffer et al. 2020; Pesko and Warman 2021; Abouk et al. 2022; Cotti et al. 2022; Friedman 2015; Dave, Feng, and Pesko 2019; Pesko, Hughes, and Faisal 2016; Pesko and Currie 2019; Friedman and Pesko 2022; Pesko 2022a), this finding provides evidence of a public health benefit from allowing ENDS sales: reduced cigarette use. This benefit should be used alongside other estimates of public health benefits and harms of ENDS, which are beyond the scope of this study, to inform the FDA's decisions on approving ENDS products.

While the FDA does not control ENDS taxes, this study's findings can still inform tobacco regulatory sciences. Specifically, FDA approving only a limited number of ENDS products may yield a more concentrated market with less options and substitutes in the product category, a result that could in turn raise consumer prices, similar to tax increases. Thus, the FDA has the ability to "tax" ENDS by approving only a limited number of products. The FDA could also ban ENDS, as done by 30 other countries (Global Tobacco Control 2018), if it determines they are not showing public health benefit. Banning ENDS would be analogous to an infinite tax increase (absent black market activity). More generally, the FDA's interest in understanding transitions across tobacco products can benefit from ENDS policy evaluation research, even studies of policies outside the FDA's purview, since these studies provide

\footnotetext{
${ }^{31}$ See here for press release of the FDA's first ENDS marketing orders, allowing their legal sale: https://www.fda.gov/news-events/press-announcements/fda-permits-marketing-e-cigarette-products-marking-firstauthorization-its-kind-agency (accessed July 9, 2022). Current premarket tobacco product marketing granted orders is provided here: Premarket Tobacco Product Marketing Granted Orders | FDA (accessed July 9, 2022).
} 
plausibly exogenous variation in ENDS use that can be leveraged to estimate the causal effect of ENDS use on subsequent combustible tobacco product use.

Due to the recency of ENDS taxation, our results are based on the experiences of ten early adopting states and two large counties. Thus, we may be capturing responses to relatively lower levels of taxes than will be in place in future periods, and the effects within these earlyadopting locations could be of limited generalizability to later-adopting locations. Still, this study's research design provides an important and useful starting point for understanding the effect of ENDS taxes on youth tobacco product use. Future work should revisit these questions as more years of data and ENDS tax variation become available. 


\section{References:}

Abouk, Rahi, and Scott Adams. 2017. "Bans on Electronic Cigarette Sales to Minors and Smoking among High School Students.” Journal of Health Economics 54: 17-24.

Abouk, Rahi, Scott Adams, Bo Feng, Johanna Catherine Maclean, and Michael F. Pesko. 2022. "The Effect of E-Cigarette Taxes on Pre-Pregnancy and Prenatal Smoking." NBER Work Pap Ser No. 26126. https://doi.org/10.3386/w26126.

Allcott, Hunt, and Charlie Rafkin. 2021. "Optimal Regulation of E-Cigarettes: Theory and Evidence.” American Economic Journal: Economic Policy, 60.

American Non-Smokers Rights Foundation. 2021. "States and Municipalities with Laws Regulating Use of Electronic Cigarettes.” April 1, 2021. https://no-smoke.org/wpcontent/uploads/pdf/ecigslaws.pdf.

Anderson, D. Mark, Kyutaro Matsuzawa, and Joseph J. Sabia. 2020. “Cigarette Taxes and Teen Marijuana Use.” National Tax Journal 73 (2): 475-510. http://dx.doi.org/10.17310/ntj.2020.2.06.

Anderson, D. Mark, and Daniel Rees. 2021. "The Public Health Effects of Legalizing Marijuana.” w28647. Cambridge, MA: National Bureau of Economic Research. https://doi.org/10.3386/w28647.

Anderson, Michael. 2008. "Multiple Inference and Gender Differences in the Effects of Early Intervention: A Reevaluation of the Abecedarian, Perry Preschool, and Early Training Projects.” Journal of the American Statistical Association 103 (484): 1481-95. https://doi.org/10.1198/016214508000000841.

Angrist, Joshua D., and Guido W. Imbens. 1995. “Two-Stage Least Squares Estimation of Average Causal Effects in Models with Variable Treatment Intensity.” Journal of the American Statistical Association 90 (430): 431-42. https://doi.org/10.1080/01621459.1995.10476535.

Balfour, David J. K., Neal L. Benowitz, Suzanne M. Colby, Dorothy K. Hatsukami, Harry A. Lando, Scott J. Leischow, Caryn Lerman, et al. 2021. "Balancing Consideration of the Risks and Benefits of E-Cigarettes.” American Journal of Public Health, August, e1-12. https://doi.org/10.2105/AJPH.2021.306416.

Benjamini, Yoav, Abba M. Krieger, and Daniel Yekutieli. 2006. “Adaptive Linear Step-up Procedures That Control the False Discovery Rate.” Biometrika 93 (3): 491-507. https://doi.org/10.1093/biomet/93.3.491.

Borusyak, Kirill, Xavier Jaravel, and Jann Spiess. 2022. "Revisiting Event Study Designs: Robust and Efficient Estimation.” arXiv. http://arxiv.org/abs/2108.12419.

Bryan, Calvin, Benjamin Hansen, Drew McNichols, and Joseph Sabia. 2020. "Do State Tobacco 21 Laws Work?” w28173. Cambridge, MA: National Bureau of Economic Research. https://doi.org/10.3386/w28173.

Callaway, Brantly, Andrew Goodman-Bacon, and Pedro H. C. Sant’Anna. 2021. "Difference-inDifferences with a Continuous Treatment.” arXiv. http://arxiv.org/abs/2107.02637.

Callaway, Brantly, and Pedro H.C. Sant’Anna. 2021. “Difference-in-Differences with Multiple Time Periods.” Journal of Econometrics 225 (2): 200-230. https://doi.org/10.1016/j.jeconom.2020.12.001.

CASAA. 2020. "History of Vaping - Historical Timeline of Events.” CASAA (blog). 2020. https:/casaa.org/education/vaping/historical-timeline-of-electronic-cigarettes/. 
Cengiz, Doruk, Arindrajit Dube, Attila Lindner, and Ben Zipperer. 2019. "The Effect of Minimum Wages on Low-Wage Jobs*.” The Quarterly Journal of Economics 134 (3): 1405-54. https://doi.org/10.1093/qje/qjz014.

Centers for Disease Control and Prevention. 2020. "Trends in the Prevalence of Tobacco Use National YRBS: 1991-2019 | YRBSS | Adolescent and School Health | CDC.” August 17, 2020.

https://www.cdc.gov/healthyyouth/data/yrbs/factsheets/2019_tobacco_trend_yrbs.htm.

Chaisemartin, Clément de, and Xavier D’Haultfoeuille. 2022. "Difference-in-Differences Estimators of Intertemporal Treatment Effects.” w29873. Cambridge, MA: National Bureau of Economic Research. https://doi.org/10.3386/w29873.

Cooper, Michael T., and Michael F. Pesko. 2017. "The Effect of E-Cigarette Indoor Vaping Restrictions on Adult Prenatal Smoking and Birth Outcomes.” J Health Econ 56: 178-90. https://doi.org/10.1016/j.jhealeco.2017.10.002.

Cotti, Chad D, Charles Courtemanche, Johanna Catherine Maclean, Erik Nesson, Michael Pesko, and Nathan Tefft. 2022. "The Effects of E-Cigarette Taxes on E-Cigarette Prices and Tobacco Product Sales: Evidence from Retail Panel Data." Journal of Health Economics.

Cotti, Chad, Erik Nesson, Michael F Pesko, Serena Phillips, and Nathan Tefft. 2021. "Standardising the Measurement of E-Cigarette Taxes in the USA, 2010-2020.” Tobacco Control, December, tobaccocontrol-2021-056865. https://doi.org/10.1136/tobaccocontrol-2021-056865.

Dave, Dhaval, Bo Feng, and Michael F Pesko. 2019. "The Effects of E-cigarette Minimum Legal Sale Age Laws on Youth Substance Use.” Health Economics 28 (3): 419-36.

Etter, Jean-François. 2018. "Gateway Effects and Electronic Cigarettes.” Addiction 113 (10): 1776-83. https://doi.org/10.1111/add.13924.

Friedman, Abigail S. 2015. "How Does Electronic Cigarette Access Affect Adolescent Smoking?” J Health Econ 44 (December): 300-308. https://doi.org/10.1016/j.jhealeco.2015.10.003.

Friedman, Abigail S., John Buckell, and Jody L. Sindelar. 2019. "Patterns of Youth Cigarette Experimentation and Onset of Habitual Smoking." American Journal of Preventive Medicine 56 (6): 803-10. https://doi.org/10.1016/j.amepre.2019.02.009.

Friedman, Abigail S., and Michael F. Pesko. 2022. "Young Adult Responses to Taxes on Cigarettes and Electronic Nicotine Delivery Systems.” Addiction, July, add.16002. https://doi.org/10.1111/add.16002.

Global Tobacco Control. 2018. "Country Laws Regulating E-Cigarettes - Sale.” November 20, 2018. https://www.globaltobaccocontrol.org/e-cigarette/sale.

Goodman-Bacon, Andrew. 2021. "Difference-in-Differences with Variation in Treatment Timing.” Journal of Econometrics, June, S0304407621001445. https://doi.org/10.1016/j.jeconom.2021.03.014.

Gruber, Jonathan, and Botond Köszegi. 2001. "Is Addiction 'Rational’? Theory and Evidence.” The Quarterly Journal of Economics 116 (4): 1261-1303.

Hansen, Benjamin, Daniel I. Rees, and Joseph J. Sabia. 2013. "Cigarette Taxes and How Youths Obtain Cigarettes.” National Tax Journal 66 (2): 371-93. https://doi.org/10.17310/ntj.2013.2.04.

Hansen, Benjamin, Joseph J. Sabia, and Daniel I. Rees. 2017. "Have Cigarette Taxes Lost Their Bite? New Estimates of the Relationship between Cigarette Taxes and Youth Smoking." 
American Journal of Health Economics 3 (1): 60-75.

https://doi.org/10.1162/AJHE_a_00067.

HealthyPeople.gov. 2020. “Adolescent Cigarette Smoking in Past 30 Days.” 2020.

https://www.healthypeople.gov/2020/data/Chart/5342?category=1\&by=Total\&fips=-1.

House Rules Committee. 2021. Build Back Better Act. https://rules.house.gov/sites/democrats.rules.house.gov/files/BILLS-117HR5376RHRCP117-18.pdf.

Katzman, Brett, Sara Markowitz, and Kerry Anne McGeary. 2007. “An Empirical Investigation of the Social Market for Cigarettes.” Health Economics 16 (10): 1025-39. https://doi.org/10.1002/hec.1215.

Marcus, Michelle, and Pedro H. C. Sant'Anna. 2021. "The Role of Parallel Trends in Event Study Settings: An Application to Environmental Economics.” Journal of the Association of Environmental and Resource Economists 8 (2): 235-75. https://doi.org/10.1086/711509.

McNeill, Ann, Leonie S Brose, Robert Calder, Linda Bauld, and Debbie Robson. 2018. “Evidence Review of E-Cigarettes and Heated Tobacco Products 2018.” London, UK: Public Health England.

https://assets.publishing.service.gov.uk/government/uploads/system/uploads/attachment_ data/file/684963/Evidence_review_of_ecigarettes_and_heated_tobacco_products_2018.pdf.

Meza, Rafael, Evelyn Jimenez-Mendoza, and David T. Levy. 2020. "Trends in Tobacco Use Among Adolescents by Grade, Sex, and Race, 1991-2019.” JAMA Network Open 3 (12): e2027465-e2027465. https://doi.org/10.1001/jamanetworkopen.2020.27465.

National Academies of Sciences, Engineering, and Medicine. 2018. "Public Health Consequences of E-Cigarettes.” Washington, DC: National Academies of Sciences, Engineering, and Medicine. https://www.nap.edu/resource/24952/012318ecigaretteHighlights.pdf.

Nesson, Erik, and Vinish Shrestha. 2021. "The Effects of False Identification Laws on Underage Alcohol-Related Traffic Fatalities.” Health Economics 30 (9): 2264-83. https://doi.org/10.1002/hec.4376.

Nguyen, Hai V. 2020. "Association of Canada's Provincial Bans on Electronic Cigarette Sales to Minors with Electronic Cigarette Use among Youths.” JAMA Pediatrics 174 (1): e193912-e193912. https://doi.org/10.1001/jamapediatrics.2019.3912.

Nutt, David J., Lawrence D. Phillips, David Balfour, H. Valerie Curran, Martin Dockrell, Jonathan Foulds, Karl Fagerstrom, et al. 2014. "Estimating the Harms of NicotineContaining Products Using the MCDA Approach.” European Addiction Research 20 (5): 218-25. https://doi.org/10.1159/000360220.

Pesko, Charles J Courtemanche, and Johanna Catherine Maclean. 2020. "The Effects of Traditional Cigarette and E-Cigarette Taxes on Adult Tobacco Product Use.” Journal of Risk \& Uncertainty 60 (3): 229-58.

Pesko, M. F., J. M. Hughes, and F. S. Faisal. 2016. “The Influence of Electronic Cigarette Age Purchasing Restrictions on Adolescent Tobacco and Marijuana Use.” Prev Med 87 (June): 207-12. https://doi.org/10.1016/j.ypmed.2016.02.001.

Pesko, M. F., D. S. Kenkel, H. Wang, and J. M. Hughes. 2016. "The Effect of Potential Electronic Nicotine Delivery System Regulations on Nicotine Product Selection.” Addiction 111 (4): 734-44. 
Pesko, Michael F. 2022a. "Effects of E-Cigarette Minimum Legal Sales Ages on Youth Tobacco Use in the United States." Journal of Risk \& Uncertainty.

. 2022b. "How Data Security Concerns Can Hinder Natural Experiment Research:

Background and Potential Solutions.” JNCI Monographs 2022 (59): 89-94.

https://doi.org/10.1093/jncimonographs/lgac007.

Pesko, Michael F., and Janet M. Currie. 2019. "E-Cigarette Minimum Legal Sale Age Laws and Traditional Cigarette Use among Rural Pregnant Teenagers.” J Health Econ 66 (July): 71-90. https://doi.org/10.1016/j.jhealeco.2019.05.003.

Pesko, and Warman. 2021. "Re-Exploring the Early Relationship between Teenage Cigarette and e-Cigarette Use Using Price and Tax Changes.” Health Economics.

Public Health Law Center. 2022. "E-Cigarette Tax: States \& Territories with Laws Taxing eCigarettes.” Saint Paul, Minnesota: Mitchell Hamline School of Law. https://www.publichealthlawcenter.org/sites/default/files/inline-files/States-with-LawsTaxing-ECigarettes-March15-2022.pdf.

Rees, Daniel I., Joseph J. Sabia, and Gokhan Kumpas. 2020. “Anti-Bullying Laws and Suicidal Behaviors among Teenagers.” w26777. National Bureau of Economic Research. https://doi.org/10.3386/w26777.

Rees, Daniel, Joseph Sabia, and Rebecca Margolit. 2021. "Minimum Wages and Teenage Childbearing: New Estimates Using a Dynamic Difference-in-Differences Approach.” w29334. Cambridge, MA: National Bureau of Economic Research. https://doi.org/10.3386/w29334.

Sabia, Joseph J., and D. Mark Anderson. 2016. “The Effect of Parental Involvement Laws on Teen Birth Control Use.” Journal of Health Economics 45 (January): 55-62. https://doi.org/10.1016/j.jhealeco.2015.10.002.

Saffer, Henry, Daniel L Dench, Michael Grossman, and Dhaval M Dave. 2020. "E-Cigarettes and Adult Smoking: Evidence from Minnesota.” Journal of Risk \& Uncertainty 30 (3).

Truth Initiative. 2019. “How Much Nicotine Is in JUUL?” Truth Initiative. February 2019. https://ruthinitiative.org/research-resources/emerging-tobacco-products/how-muchnicotine-juul.

UK Committee on Toxicity of Chemicals in Food, Consumer Products and the Environment. 2020. "Statement on the Potential Toxicological Risks from Electronic Nicotine (and Non-Nicotine) Delivery Systems (E(N)NDS - e-Cigarettes).” https://cot.food.gov.uk/sites/default/files/202009/COT\%20E\%28N\%29NDS\%20statement\%202020-04.pdf.

US Department of Health Human Services. 2012. "Preventing Tobacco Use among Youth and Young Adults: A Report of the Surgeon General.” US Department of Health Human Services.

US Surgeon General. 2014. "The Health Consequences of Smoking -- 50 Years of Progress: A Report of the Surgeon General.” https://doi.org/10.1037/e510072014-001. . 2016. "E-Cigarette Use Among Youth and Young Adults: A Report of the Surgeon General.” Washington, DC: Department of Health and Human Services. . 2018. "Surgeon General's Advisory on E-Cigarette Use Among Youth.” Washington, DC: Department of Health and Human Services. https://ecigarettes.surgeongeneral.gov/documents/surgeon-generals-advisory-on-e-cigarette-useamong-youth-2018.pdf. 
Viscusi, W. Kip. 2016. “Risk Beliefs and Preferences for E-Cigarettes.” American Journal of Health Economics 2 (2): 213-40. https://doi.org/10.1162/AJHE_a_00042.

Wooldridge, Jeffrey M. 2010. Econometric Analysis of Cross Section and Panel Data. 2nd ed. Cambridge, Mass: MIT Press. 
Table 1. ENDS Tax Changes Through 2nd Quarter of 2019

\begin{tabular}{|c|c|c|c|c|c|c|}
\hline Locality & Effective Date & Unit Taxed & Tax Amount & $\begin{array}{c}\text { Tax per ml, } \\
\text { Q1-2 } 2015(\$) \\
\end{array}$ & $\begin{array}{c}\text { Tax per ml, } \\
\text { Q1-2 } 2017(\$) \\
\end{array}$ & $\begin{array}{c}\text { Tax per ml, } \\
\text { Q1-2 } 2019(\$)\end{array}$ \\
\hline \multicolumn{7}{|l|}{ District/State } \\
\hline California & $\begin{array}{c}\text { 4/2017, 7/2017, } \\
7 / 2018\end{array}$ & Wholesale price & $\begin{array}{c}27.3 \%, 65.1 \%, \\
62.8 \%\end{array}$ & $\$ 0$ & $\$ 0.72$ & $\$ 1.65$ \\
\hline Delaware & $1 / 2018$ & Per fluid milliliter & $\$ 0.05$ & $\$ 0$ & $\$ 0$ & $\$ 0.05$ \\
\hline Kansas & 1/2017, 7/2017 & Per fluid milliliter & $\$ 0.20, \$ 0.05$ & $\$ 0$ & $\$ 0.20$ & $\$ 0.05$ \\
\hline Louisiana & 7/2015 & Per fluid milliliter & $\$ 0.05$ & $\$ 0$ & $\$ 0.05$ & $\$ 0.05$ \\
\hline Minnesota & 8/2010, 7/2013 & Wholesale price & $35.0 \%, 95.0 \%$ & $\$ 2.49$ & $\$ 2.49$ & $\$ 2.49$ \\
\hline North Carolina & 6/2015 & Per fluid milliliter & $\$ 0.05$ & $\$ 0.02$ & $\$ 0.05$ & $\$ 0.05$ \\
\hline New Jersey & $10 / 2018$ & Per fluid milliliter & $\$ 0.10$ & $\$ 0$ & $\$ 0$ & $\$ 0.10$ \\
\hline Pennsylvania & 7/2016 & Wholesale price & $40.0 \%$ & $\$ 0$ & $\$ 1.05$ & $\$ 1.05$ \\
\hline Washington, DC & $\begin{array}{l}\text { 10/2015, 10/2016, } \\
10 / 2017,10 / 2018\end{array}$ & Wholesale price & $\begin{array}{c}67.0 \%, 65.0 \%, 60 \% \\
96 \%\end{array}$ & $\$ 0$ & $\$ 1.70$ & $\$ 2.52$ \\
\hline West Virginia & $7 / 2016$ & Per fluid milliliter & $\$ 0.08$ & $\$ 0$ & $\$ 0.08$ & $\$ 0.08$ \\
\hline \multicolumn{7}{|l|}{ County/City } \\
\hline Chicago, Illinois & 1/2016, 1/2019 & $\begin{array}{l}\text { Per container / per } \\
\text { fluid milliliter }{ }^{1}\end{array}$ & $\begin{array}{c}\$ 0.80 / \$ 0.55, \$ 1.50 / \\
\$ 1.20\end{array}$ & & & \\
\hline $\begin{array}{l}\text { Cook County, IL } \\
\text { Montgomery County, }\end{array}$ & $5 / 2016$ & Per fluid milliliter & $\$ 0.20$ & $\$ 0$ & $\$ 0.94$ & $\$ 1.50$ \\
\hline $\mathrm{MD}$ & 8/2015 & Wholesale price & $30.00 \%$ & $\$ 0$ & $\$ 0.79$ & $\$ 0.79$ \\
\hline
\end{tabular}

Notes: Please see the online data appendix for further details. ${ }^{1}$ The Chicago tax is added to the Cook County tax based on the share of the population residing in Chicago. 
Table 2: Descriptive Statistics, 2014-2019 (MTF); 2015-2019 (YRBSS)

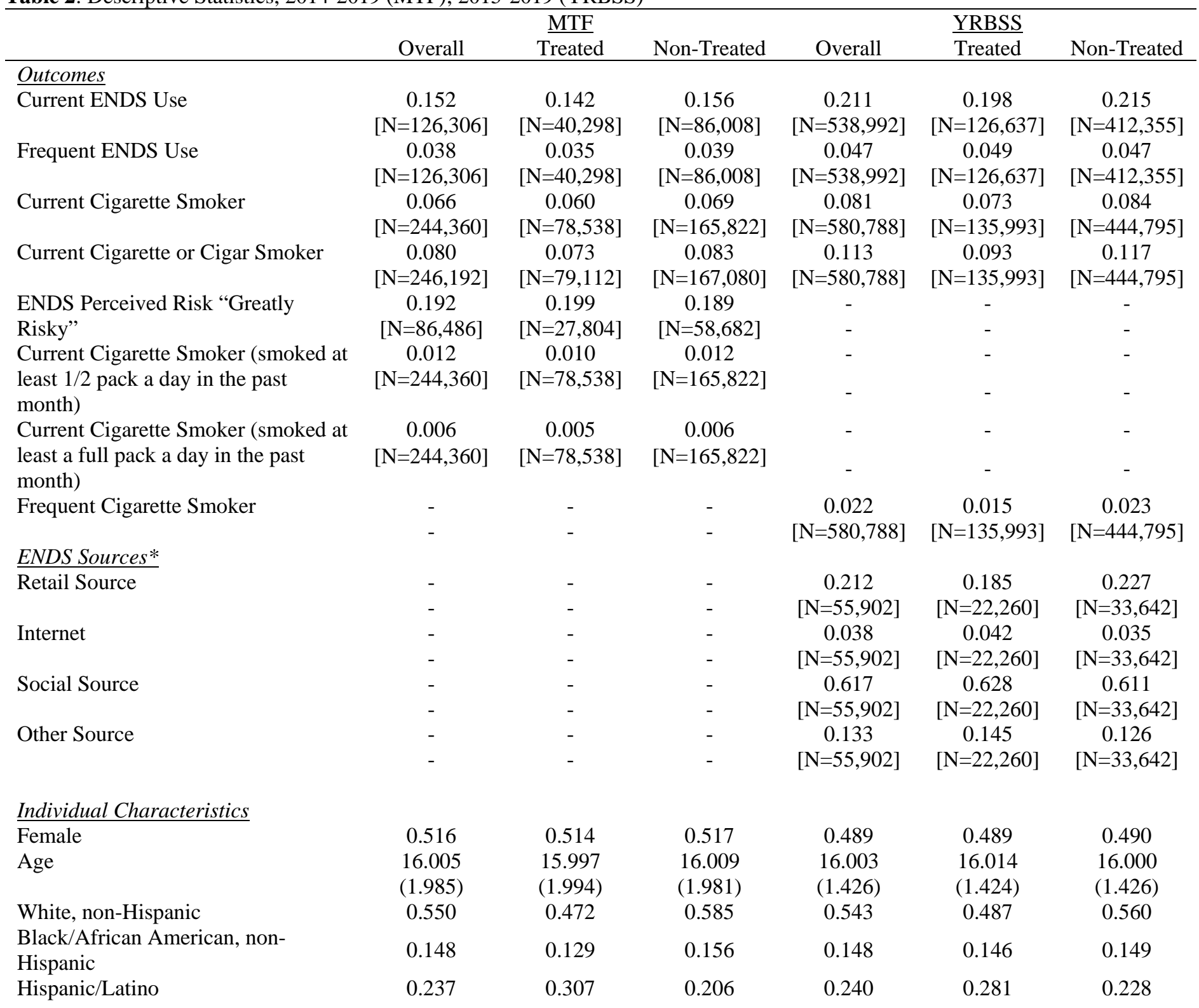




\begin{tabular}{|c|c|c|c|c|c|c|}
\hline $\begin{array}{l}\text { Other Races, non-Hispanic } \\
\text { Grade }\end{array}$ & $\begin{array}{c}0.066 \\
10.050 \\
(1.665)\end{array}$ & $\begin{array}{c}0.092 \\
10.083 \\
(1.647)\end{array}$ & $\begin{array}{c}0.054 \\
10.035 \\
(1.673)\end{array}$ & $\begin{array}{c}0.068 \\
10.445 \\
(1.190)\end{array}$ & $\begin{array}{c}0.085 \\
10.481 \\
(1.195)\end{array}$ & $\begin{array}{c}0.063 \\
10.434 \\
(1.188)\end{array}$ \\
\hline ENDS Tax Rate per ml (2019 \$) & $\begin{array}{c}0.174 \\
(0.516)\end{array}$ & $\begin{array}{c}0.562 \\
(0.801)\end{array}$ & $\begin{array}{l}- \\
-\end{array}$ & $\begin{array}{c}0.166 \\
(0.456)\end{array}$ & $\begin{array}{c}0.703 \\
(0.709)\end{array}$ & $\begin{array}{l}- \\
-\end{array}$ \\
\hline Cigarette Tax Rate per Pack (2019 \$) & $\begin{array}{c}2.967 \\
(1.379)\end{array}$ & $\begin{array}{c}3.137 \\
(1.421)\end{array}$ & $\begin{array}{c}2.890 \\
(1.353)\end{array}$ & $\begin{array}{c}2.954 \\
(1.285)\end{array}$ & $\begin{array}{c}3.260 \\
(0.972)\end{array}$ & $\begin{array}{c}2.859 \\
(1.353)\end{array}$ \\
\hline $\begin{array}{l}\text { Tobacco } 21 \text { Percent Population } \\
\text { Coverage }\end{array}$ & 0.146 & 0.300 & 0.077 & 0.174 & 0.462 & 0.085 \\
\hline $\begin{array}{l}\text { ENDS Minimum Legal Sale Age } \\
(0 / 1)\end{array}$ & 0.873 & 0.936 & 0.844 & 0.924 & 1.000 & 0.900 \\
\hline Recreational Marijuana Laws (0/1) & 0.128 & 0.218 & 0.087 & 0.163 & 0.378 & 0.096 \\
\hline Medical Marijuana Laws (0/1) & 0.526 & 0.761 & 0.420 & 0.579 & 0.807 & 0.508 \\
\hline Vertical License Law (0/1) & 0.968 & 0.963 & 0.970 & 0.975 & 0.959 & 0.980 \\
\hline Unemployment Rate & $\begin{array}{c}4.862 \\
(1.576)\end{array}$ & $\begin{array}{c}5.195 \\
(1.732)\end{array}$ & $\begin{array}{c}4.713 \\
(1.476)\end{array}$ & $\begin{array}{c}4.544 \\
(0.880)\end{array}$ & $\begin{array}{c}4.480 \\
(0.499)\end{array}$ & $\begin{array}{c}4.563 \\
(0.967)\end{array}$ \\
\hline Poverty Rates & $\begin{array}{l}14.200 \\
(5.219)\end{array}$ & $\begin{array}{l}14.076 \\
(4.764)\end{array}$ & $\begin{array}{l}14.256 \\
(5.411)\end{array}$ & $\begin{array}{l}12.697 \\
(2.513)\end{array}$ & $\begin{array}{l}12.015 \\
(2.693)\end{array}$ & $\begin{array}{l}12.908 \\
(2.416)\end{array}$ \\
\hline $\mathrm{N}$ & 254,516 & 81,823 & 172,693 & 600,877 & 139,509 & 461,368 \\
\hline
\end{tabular}

Notes: Means and standard deviations (in parenthesis) are reported. Since state/county-level information is available in the MTF data, policy/economic controls are at the county level except for beer taxes, marijuana laws, and vertical ID laws in which we only have state-level data. Since county information is not available in the national / state YRBSS, available county-level information is population-weighted to the state level.

*ENDS sources are only for the years 2017-2019 and are conditional on an individual being a current ENDS user. 
Table 3: Main Results

Panel A: Effects of ENDS Tax on ENDS Use

\begin{tabular}{|c|c|c|c|c|c|}
\hline Outcome & $\begin{array}{c}\text { Current ENDS } \\
\text { User } \\
\end{array}$ & $\begin{array}{c}\text { Regular ENDS } \\
\text { User }\end{array}$ & $\begin{array}{c}\text { ENDS } \\
\text { Initiation }\end{array}$ & $\begin{array}{c}\text { Ever Use } \\
\text { ENDS }\end{array}$ & $\begin{array}{c}\text { Current ENDS } \\
\text { User } \\
\end{array}$ \\
\hline \multirow[t]{4}{*}{ ENDS Tax Rate per ml (2019 \$) } & $-0.019+$ & $-0.013+$ & -0.008 & $-0.052 * * *$ & $-0.071 * *$ \\
\hline & $(0.010)$ & $(0.007)$ & $(0.014)$ & $(0.010)$ & $(0.025)$ \\
\hline & {$[-0.040,0.002]$} & {$[-0.028,0.001]$} & {$[-0.036,0.021]$} & {$[-0.072,-0.031]$} & {$[-0.120,-0.022]$} \\
\hline & $<0.071>$ & $<0.073>$ & $<0.581>$ & $<0.000>$ & $<0.006>$ \\
\hline \multirow{4}{*}{ Cigarette Tax Rate per Pack (2019 \$) } & -0.005 & $0.009+$ & -0.003 & 0.012 & 0.041 \\
\hline & $(0.008)$ & $(0.005)$ & $(0.013)$ & $(0.008)$ & $(0.026)$ \\
\hline & {$[-0.021,0.012]$} & {$[-0.001,0.019]$} & {$[-0.029,0.022]$} & {$[-0.004,0.028]$} & {$[-0.012,0.094]$} \\
\hline & $<0.552>$ & $<0.065>$ & $<0.789>$ & $<0.135>$ & $<0.129>$ \\
\hline Data & MTF & MTF & MTF & MTF & YRBSS \\
\hline Years & 2014-2019 & 2014-2019 & 2015-2019 & 2015-2019 & 2015-2019 \\
\hline $\mathrm{N}$ & 126,306 & 126,306 & 66,124 & 85,541 & 538,992 \\
\hline Dependent Variable Mean & 0.152 & 0.038 & 0.104 & 0.287 & 0.213 \\
\hline ENDS Elasticity & -0.075 & -0.212 & -0.059 & -0.146 & -0.164 \\
\hline Cigarette Elasticity & -0.095 & 0.712 & -0.097 & 0.127 & 0.568 \\
\hline
\end{tabular}

Panel B: Effects of ENDS Tax on ENDS Perceived Risk and Sources

\begin{tabular}{|c|c|c|c|c|c|}
\hline Outcome & $\begin{array}{c}\text { ENDS Perceived } \\
\text { Risk }\end{array}$ & Retail Source & Social Source & Internet Source & Other Source \\
\hline \multirow[t]{4}{*}{ ENDS Tax Rate per ml (2019 \$) } & $0.029 *$ & $-0.076^{*}$ & $0.101^{*}$ & 0.019 & $-0.044^{*}$ \\
\hline & $(0.014)$ & $(0.034)$ & $(0.046)$ & $(0.015)$ & $(0.021)$ \\
\hline & {$[0.001,0.057]$} & {$[-0.143,-0.008]$} & {$[0.008,0.194]$} & {$[-0.012,0.049]$} & {$[-0.086,-0.002]$} \\
\hline & $<0.041>$ & $<0.029>$ & $<0.034>$ & $<0.220>$ & $<0.040>$ \\
\hline \multirow[t]{4}{*}{ Cigarette Tax Rate per Pack (2019 \$) } & -0.003 & $0.086 * *$ & $-0.105^{*}$ & 0.006 & 0.014 \\
\hline & $(0.007)$ & $(0.031)$ & $(0.049)$ & $(0.019)$ & $(0.021)$ \\
\hline & {$[-0.017,0.011]$} & {$[0.023,0.148]$} & {$[-0.204,-0.006]$} & {$[-0.032,0.044]$} & {$[-0.029,0.056]$} \\
\hline & $<0.671>$ & $<0.009>$ & $<0.038>$ & $<0.747>$ & $<0.522>$ \\
\hline Data & MTF & YRBSS & YRBSS & YRBSS & YRBSS \\
\hline Years & 2014-2018 & 2017-2019 & 2017-2019 & 2017-2019 & 2017-2019 \\
\hline $\mathrm{N}$ & 86,486 & 55,902 & 55,902 & 55,902 & 55,902 \\
\hline Dependent Variable Mean & 0.192 & 0.185 & 0.627 & 0.042 & 0.145 \\
\hline
\end{tabular}


Panel C: Effects of ENDS Tax on Combustible Tobacco Product Use

\begin{tabular}{|c|c|c|c|c|c|c|c|}
\hline Outcome & $\begin{array}{c}\text { Current } \\
\text { Cigarette Use } \\
\end{array}$ & $\begin{array}{c}\text { Current } \\
\text { Cigarette Use } \\
\text { (half pack a } \\
\text { day) }\end{array}$ & $\begin{array}{c}\text { Current } \\
\text { Cigarette or } \\
\text { Cigar Use }\end{array}$ & $\begin{array}{c}\text { Current } \\
\text { Cigarette Use }\end{array}$ & $\begin{array}{c}\text { Regular } \\
\text { Cigarette Use } \\
\end{array}$ & $\begin{array}{c}\text { Daily Cigarette } \\
\text { Use }\end{array}$ & $\begin{array}{c}\text { Current } \\
\text { Cigarette or } \\
\text { Cigar Use } \\
\end{array}$ \\
\hline \multirow{4}{*}{$\begin{array}{l}\text { ENDS Tax Rate } \\
\text { per ml (2019 \$) }\end{array}$} & $0.013^{*}$ & $0.006^{* *}$ & $0.012+$ & 0.008 & 0.016 & 0.014 & 0.007 \\
\hline & $(0.006)$ & $(0.002)$ & $(0.006)$ & $(0.013)$ & $(0.014)$ & $(0.012)$ & $(0.016)$ \\
\hline & {$[0.001,0.026]$} & {$[0.002,0.010]$} & {$[-0.001,0.024]$} & {$[-0.019,0.035]$} & {$[-0.011,0.043]$} & {$[-0.011,0.039]$} & {$[-0.024,0.038]$} \\
\hline & $<0.041>$ & $<0.008>$ & $<0.069>$ & $<0.544>$ & $<0.244>$ & $<0.257>$ & $<0.658>$ \\
\hline \multirow{4}{*}{$\begin{array}{l}\text { Cigarette Tax Rate } \\
\text { per Pack (2019 \$) }\end{array}$} & -0.001 & -0.002 & -0.002 & -0.010 & -0.012 & -0.008 & -0.011 \\
\hline & $(0.005)$ & $(0.002)$ & $(0.007)$ & $(0.013)$ & $(0.014)$ & $(0.012)$ & $(0.017)$ \\
\hline & {$[-0.011,0.010]$} & {$[-0.005,0.001]$} & {$[-0.015,0.012]$} & {$[-0.035,0.016]$} & {$[-0.039,0.016]$} & {$[-0.033,0.016]$} & {$[-0.045,0.023]$} \\
\hline & $<0.892>$ & $<0.227>$ & $<0.819>$ & $<0.544>$ & $<0.398>$ & $<0.491>$ & $<0.502>$ \\
\hline Data & MTF & MTF & MTF & YRBSS & YRBSS & YRBSS & YRBSS \\
\hline Years & 2014-2019 & 2014-2019 & 2014-2019 & 2015-2019 & 2015-2019 & 2015-2019 & 2015-2019 \\
\hline $\mathrm{N}$ & 244,360 & 244,360 & 246,192 & 580,788 & 580,788 & 580,788 & 504,639 \\
\hline $\begin{array}{l}\text { Dependent Variable } \\
\text { Mean }\end{array}$ & 0.066 & 0.012 & 0.080 & 0.080 & 0.019 & 0.014 & 0.107 \\
\hline ENDS Elasticity & 0.123 & 0.341 & 0.089 & 0.041 & 0.336 & 0.412 & 0.031 \\
\hline Cigarette Elasticity & -0.032 & -0.530 & -0.056 & -0.355 & -1.792 & -1.784 & -0.321 \\
\hline
\end{tabular}

$+\mathrm{p}<0.10, * \mathrm{p}<0.05$

Notes: All MTF models include tax jurisdiction fixed-effects, year-by-quarter fixed-effects, and each of the individual controls and policy/economic covariates listed in Table 2. All YRBSS models include state fixed-effects, year fixed-effects, and each of the individual controls and policy/economic covariates listed in Table 2. Regressions are weighted, standard errors are corrected for clustering at the state level, 95\% confidence intervals are shown in [ ] and p-values are shown in $<>$. 
Table 4: Effects of ENDS Tax on Dual and Any Use

\begin{tabular}{|c|c|c|c|c|}
\hline Outcome & Current Dual Use & Current Any Use & Current Dual Use & Current Any Use \\
\hline \multirow[t]{4}{*}{ ENDS Tax Rate per ml (2019 \$) } & 0.004 & -0.01 & 0.005 & -0.046 \\
\hline & $(0.004)$ & $(0.013)$ & $(0.012)$ & $(0.034)$ \\
\hline & {$[-0.004,0.012]$} & {$[-0.036,0.017]$} & {$[-0.020,0.030]$} & {$[-0.115,0.034]$} \\
\hline & $<0.371>$ & $<0.462>$ & $<0.701>$ & $<0.187>$ \\
\hline \multirow[t]{4}{*}{ Cigarette Tax Rate per Pack (2019 \$) } & 0.002 & -0.004 & -0.004 & 0.035 \\
\hline & $(0.004)$ & $(0.010)$ & $(0.012)$ & $(0.028)$ \\
\hline & {$[-0.006,0.009]$} & {$[-0.024,0.016]$} & {$[-0.028,0.021]$} & {$[-0.021,0.091]$} \\
\hline & $<0.691>$ & $<0.682>$ & $<0.775>$ & $<0.216>$ \\
\hline Data & MTF & MTF & YRBSS & YRBSS \\
\hline Years & 2014-2019 & 2014-2019 & 2015-2019 & 2015-2019 \\
\hline $\mathrm{N}$ & 123,631 & 123,631 & 524,842 & 474,336 \\
\hline Dependent Variable Mean & 0.041 & 0.178 & 0.059 & 0.231 \\
\hline ENDS Elasticity & 0.053 & -0.033 & 0.032 & -0.093 \\
\hline Cigarette Elasticity & 0.112 & -0.068 & -0.177 & 0.455 \\
\hline
\end{tabular}

$+\mathrm{p}<0.10, * \mathrm{p}<0.05, * * \mathrm{p}<0.01, * * * \mathrm{p}<0.001$

Notes: All MTF models include tax jurisdiction fixed-effects, year-by-quarter fixed-effects, and each of the individual controls and policy/economic covariates listed in Table 2. All YRBSS models include state fixed-effects, year fixed-effects, and each of the individual controls and policy/economic covariates listed in Table 2. Regressions are weighted, standard errors are corrected for clustering at the state level, 95\% confidence intervals are shown in [ ] and p-values are shown in $<>$. 
Table 5: Sensitivity Analysis, Adding One Period Lead

Panel A: Effects of ENDS Tax on ENDS Use and ENDS Perceived Risk

\begin{tabular}{|c|c|c|c|c|c|c|}
\hline Outcome & $\begin{array}{c}\text { Current ENDS } \\
\text { User }\end{array}$ & $\begin{array}{c}\text { Regular ENDS } \\
\text { User }\end{array}$ & $\begin{array}{c}\text { ENDS } \\
\text { Initiation }\end{array}$ & $\begin{array}{c}\text { Ever Use } \\
\text { ENDS }\end{array}$ & $\begin{array}{c}\text { Current ENDS } \\
\text { User }\end{array}$ & $\begin{array}{c}\text { ENDS Perceived } \\
\text { Risk }\end{array}$ \\
\hline \multirow[t]{4}{*}{ ENDS Tax Lead $(0,1)$} & -0.001 & 0.005 & 0.008 & 0.003 & 0.017 & 0.002 \\
\hline & $(0.013)$ & $(0.006)$ & $(0.011)$ & $(0.014)$ & $(0.021)$ & $(0.009)$ \\
\hline & {$[-0.027,0.025]$} & {$[-0.006,0.016]$} & {$[-0.014,0.030]$} & {$[-0.026,0.031]$} & {$[-0.024,0.059]$} & {$[-0.016,0.019]$} \\
\hline & $<0.952>$ & $<0.364>$ & $<0.476>$ & $<0.856>$ & $<0.406>$ & $<0.849>$ \\
\hline \multirow[t]{4}{*}{ ENDS Tax Rate per ml (2019 \$) } & $-0.020+$ & $-0.012+$ & -0.005 & $-0.051^{* * *}$ & $-0.061 * *$ & $0.029 *$ \\
\hline & $(0.010)$ & $(0.007)$ & $(0.013)$ & $(0.012)$ & $(0.021)$ & $(0.014)$ \\
\hline & {$[-0.041,0.001]$} & {$[-0.026,0.002]$} & {$[-0.031,0.021]$} & {$[-0.074,-0.027]$} & {$[-0.104,-0.018]$} & {$[0.001,0.058]$} \\
\hline & $<0.068>$ & $<0.098>$ & $<0.695>$ & $<0.000>$ & $<0.006>$ & $<0.043>$ \\
\hline & -0.005 & $0.010+$ & -0.002 & 0.012 & 0.036 & -0.003 \\
\hline \multirow{4}{*}{$(2019 \$)$} & $(0.008)$ & $(0.005)$ & $(0.013)$ & $(0.008)$ & $(0.024)$ & $(0.007)$ \\
\hline & {$[-0.021,0.011]$} & {$[-0.000,0.020]$} & {$[-0.029,0.024]$} & {$[-0.004,0.029]$} & {$[-0.012,0.083]$} & {$[-0.017,0.012]$} \\
\hline & $<0.540>$ & $<0.059>$ & $<0.853>$ & $<0.129>$ & $<0.136>$ & $<0.708>$ \\
\hline & -0.001 & 0.005 & 0.008 & 0.003 & 0.017 & 0.002 \\
\hline Data & MTF & MTF & MTF & MTF & YRBSS & MTF \\
\hline Years & 2014-2019 & 2014-2019 & 2015-2019 & 2015-2019 & 2015-2019 & 2014-2018 \\
\hline $\mathrm{N}$ & 126,306 & 126,306 & 66,124 & 85,541 & 538,992 & 86,486 \\
\hline Dependent Variable Mean & 0.152 & 0.038 & 0.104 & 0.287 & 0.213 & 0.192 \\
\hline
\end{tabular}


Panel B: Effects of ENDS Tax on Combustible Tobacco Product Use

\begin{tabular}{|c|c|c|c|c|c|c|c|}
\hline Outcome & $\begin{array}{c}\text { Current } \\
\text { Cigarette Use }\end{array}$ & $\begin{array}{c}\text { Current } \\
\text { Cigarette Use } \\
\text { (half pack a } \\
\text { day) }\end{array}$ & $\begin{array}{c}\text { Current } \\
\text { Cigarette or } \\
\text { Cigar Use }\end{array}$ & $\begin{array}{c}\text { Current } \\
\text { Cigarette Use }\end{array}$ & $\begin{array}{c}\text { Regular } \\
\text { Cigarette Use }\end{array}$ & $\begin{array}{l}\text { Daily Cigarette } \\
\text { Use }\end{array}$ & $\begin{array}{c}\text { Current } \\
\text { Cigarette or } \\
\text { Cigar Use }\end{array}$ \\
\hline \multirow[t]{4}{*}{ ENDS Tax Lead $(0,1)$} & -0.003 & -0.002 & -0.003 & 0.004 & 0.002 & 0.0005 & 0.0005 \\
\hline & $(0.006)$ & $(0.002)$ & $(0.007)$ & $(0.008)$ & $(0.006)$ & $(0.006)$ & $(0.010)$ \\
\hline & {$[-0.015,0.009]$} & {$[-0.006,0.002]$} & {$[-0.016,0.010]$} & {$[-0.012,0.021]$} & {$[-0.011,0.014]$} & {$[-0.012,0.013]$} & {$[-0.019,0.020]$} \\
\hline & $<0.646>$ & $<0.358>$ & $<0.643>$ & $<0.607>$ & $<0.794>$ & $<0.942>$ & $<0.960>$ \\
\hline \multirow{4}{*}{$\begin{array}{l}\text { ENDS Tax Rate } \\
(2019 \$)\end{array}$} & $0.012 *$ & $0.006^{*}$ & $0.011+$ & 0.011 & 0.017 & 0.015 & 0.007 \\
\hline & $(0.005)$ & $(0.002)$ & $(0.006)$ & $(0.010)$ & $(0.011)$ & $(0.010)$ & $(0.014)$ \\
\hline & {$[0.001,0.023]$} & {$[0.001,0.010]$} & {$[-0.001,0.022]$} & {$[-0.009,0.031]$} & {$[-0.006,0.040]$} & {$[-0.006,0.035]$} & {$[-0.021,0.036]$} \\
\hline & $<0.029>$ & $<0.012>$ & $<0.066>$ & $<0.291>$ & $<0.145>$ & $<0.166>$ & $<0.612>$ \\
\hline \multirow{4}{*}{$\begin{array}{l}\text { Cigarette Tax Rate } \\
(2019 \$)\end{array}$} & -0.001 & -0.002 & -0.002 & -0.010 & -0.012 & -0.009 & -0.012 \\
\hline & $(0.006)$ & $(0.002)$ & $(0.007)$ & $(0.012)$ & $(0.013)$ & $(0.012)$ & $(0.017)$ \\
\hline & {$[-0.012,0.010]$} & {$[-0.006,0.001]$} & {$[-0.016,0.012]$} & {$[-0.034,0.013]$} & {$[-0.038,0.015]$} & {$[-0.032,0.015]$} & {$[-0.045,0.022]$} \\
\hline & $<0.855>$ & $<0.187>$ & $<0.787>$ & $<0.378>$ & $<0.372>$ & $<0.471>$ & $<0.492>$ \\
\hline Data & MTF & MTF & MTF & YRBSS & YRBSS & YRBSS & YRBSS \\
\hline Years & 2014-2019 & 2014-2019 & 2014-2019 & 2015-2019 & 2015-2019 & 2015-2019 & 2015-2019 \\
\hline $\mathrm{N}$ & 244,360 & 244,360 & 246,192 & 580,788 & 580,788 & 580,788 & 504,639 \\
\hline $\begin{array}{l}\text { Dependent Variable } \\
\text { Mean }\end{array}$ & 0.066 & 0.012 & 0.080 & 0.080 & 0.019 & 0.014 & 0.107 \\
\hline
\end{tabular}

$+\mathrm{p}<0.10, * \mathrm{p}<0.05, * * \mathrm{p}<0.01, * * * \mathrm{p}<0.001$

Notes: All MTF models include tax jurisdiction fixed-effects, year-by-quarter fixed-effects, and each of the individual controls and policy/economic covariates listed in Table 2. All YRBSS models include state fixed-effects, year fixed-effects, and each of the individual controls and policy/economic covariates listed in Table 2. Regressions are weighted, standard errors are corrected for clustering at the state level, 95\% confidence intervals are shown in [ ] and p-values are shown in $<>$. 
Table 6: Sensitivity Analysis, Alternative Estimation Methods

\begin{tabular}{|c|c|c|c|c|c|c|c|}
\hline Outcome & $\begin{array}{c}\text { Current ENDS } \\
\text { User }\end{array}$ & $\begin{array}{c}\text { Regular ENDS } \\
\text { User }\end{array}$ & Ever Use ENDS & $\begin{array}{c}\text { ENDS } \\
\text { Perceived Risks }\end{array}$ & $\begin{array}{c}\text { Current } \\
\text { Cigarette Use }\end{array}$ & $\begin{array}{c}\text { Current } \\
\text { Cigarette Use } \\
\text { (half pack a } \\
\text { day) }\end{array}$ & $\begin{array}{c}\text { Current } \\
\text { Cigarette or } \\
\text { Cigar Use }\end{array}$ \\
\hline Baseline (Table 3) & $\begin{array}{c}-0.019+ \\
(0.010)\end{array}$ & $\begin{array}{c}-0.013+ \\
(0.007)\end{array}$ & $\begin{array}{c}-0.052 * * * \\
(0.010)\end{array}$ & $\begin{array}{l}0.029^{*} \\
(0.014)\end{array}$ & $\begin{array}{l}0.013^{*} \\
(0.006)\end{array}$ & $\begin{array}{l}0.006^{* *} \\
(0.002)\end{array}$ & $\begin{array}{l}0.012+ \\
(0.006)\end{array}$ \\
\hline $\mathrm{IV}^{\wedge}$ & $\begin{array}{c}{[126,306]} \\
-0.020 \\
(0.012) \\
{[126.306]}\end{array}$ & $\begin{array}{c}{[126,306]} \\
-0.014 \\
(0.008) \\
{[126,306]}\end{array}$ & $\begin{array}{c}{[85,541]} \\
-0.050 * * * \\
(0.012) \\
{[85,541]}\end{array}$ & $\begin{array}{c}{[86,486]} \\
0.033^{*} \\
(0.014) \\
86,486\end{array}$ & $\begin{array}{c}{[244,360]} \\
0.012+ \\
(0.007) \\
{[244.360]}\end{array}$ & $\begin{array}{c}{[244,360]} \\
0.006^{*} \\
(0.002) \\
{[244,360]}\end{array}$ & $\begin{array}{c}{[246,192]} \\
0.011 \\
(0.007) \\
{[246.192]}\end{array}$ \\
\hline Stacked DID & $\begin{array}{c}-0.018+ \\
(0.010) \\
{[649,259]}\end{array}$ & $\begin{array}{c}-0.011 \\
(0.007) \\
{[649,259]}\end{array}$ & $\begin{array}{c}-0.039 * * * \\
(0.008) \\
{[420,214]}\end{array}$ & $\begin{array}{c}0.022+ \\
(0.011) \\
515,496\end{array}$ & $\begin{array}{c}0.008 \\
(0.005) \\
{[1,313,040]}\end{array}$ & $\begin{array}{c}0.004^{*} \\
(0.002) \\
{[1,313,040]}\end{array}$ & $\begin{array}{c}0.008 \\
(0.006) \\
{[1,323,656]}\end{array}$ \\
\hline $\begin{array}{l}\text { de Chaisemartin \& } \\
\text { D'Haultfœuille (2022) }\end{array}$ & $\begin{array}{c}-0.081 \\
(0.080) \\
{[726]}\end{array}$ & $\begin{array}{c}-0.029 \\
(0.034) \\
{[726]}\end{array}$ & $\begin{array}{c}-0.153+ \\
(0.092) \\
{[726]}\end{array}$ & $\begin{array}{l}0.108 \\
0.135 \\
{[504]}\end{array}$ & $\begin{array}{c}0.049 \\
(0.046) \\
{[726]}\end{array}$ & $\begin{array}{c}0.021 \\
(0.017) \\
{[726]}\end{array}$ & $\begin{array}{c}0.034 \\
(0.049) \\
{[726]}\end{array}$ \\
\hline $\begin{array}{l}\text { Data } \\
\text { Years }\end{array}$ & $\begin{array}{c}\text { MTF } \\
2014-2019\end{array}$ & $\begin{array}{c}\text { MTF } \\
2014-2019\end{array}$ & $\begin{array}{c}\text { MTF } \\
2015-2019\end{array}$ & $\begin{array}{c}\text { MTF } \\
2014-2018\end{array}$ & $\begin{array}{c}\text { MTF } \\
2014-2019\end{array}$ & $\begin{array}{c}\text { MTF } \\
2014-2019\end{array}$ & $\begin{array}{c}\text { MTF } \\
2014-2019\end{array}$ \\
\hline
\end{tabular}

$+\mathrm{p}<0.10, * \mathrm{p}<0.05, * * \mathrm{p}<0.01, * * * \mathrm{p}<0.001$

Notes: Estimated coefficients for ENDS tax rate per ml (2019 \$) reported. All MTF models include tax jurisdiction fixed-effects, year-by-quarter fixed-effects, and each of the individual controls and policy/economic covariates listed in Table 2. We estimate these alternative estimation methods using only MTF because YRBSS is otherwise limited by having only three waves of data for e-cigarette use outcomes and by a lack of substate information used in the stacked DID model. Regressions are weighted (or in application of de Chaisemartin \& D'Haultfœuille [2022] the regression is estimated using aggregate data in which weights were applied at the time of collapsing), standard errors are corrected for clustering at the state level, estimate sample sizes are shown in [ ]. ^ First-stage Fstatistics all exceed 10,000. 
Figure 1: Weighted ENDS and Cigarette Tax Rates Over Time

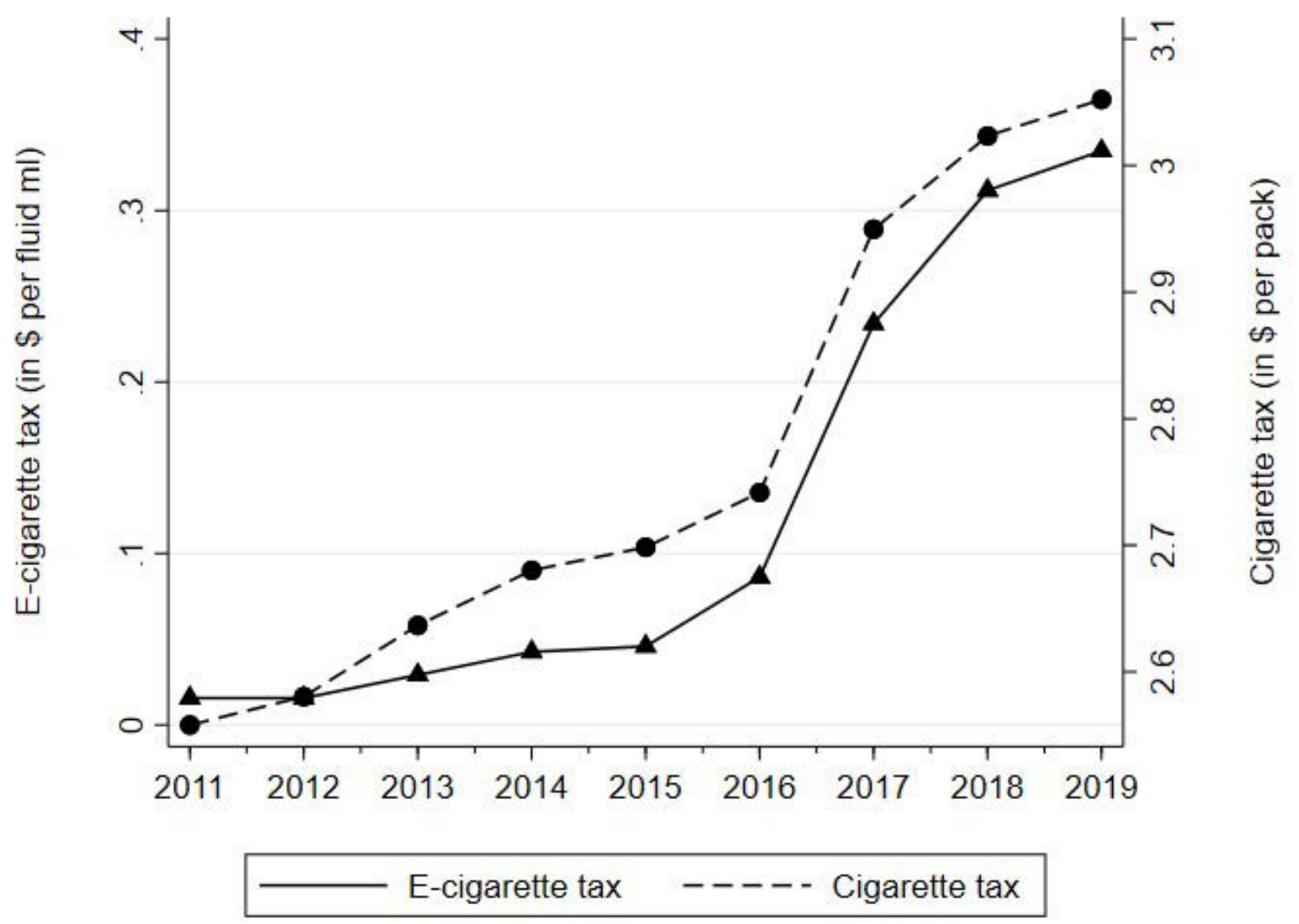


Figure 2: Heterogeneity Check, Box-Whisker Graphs for Standardized ENDS Tax Rate (MTF)
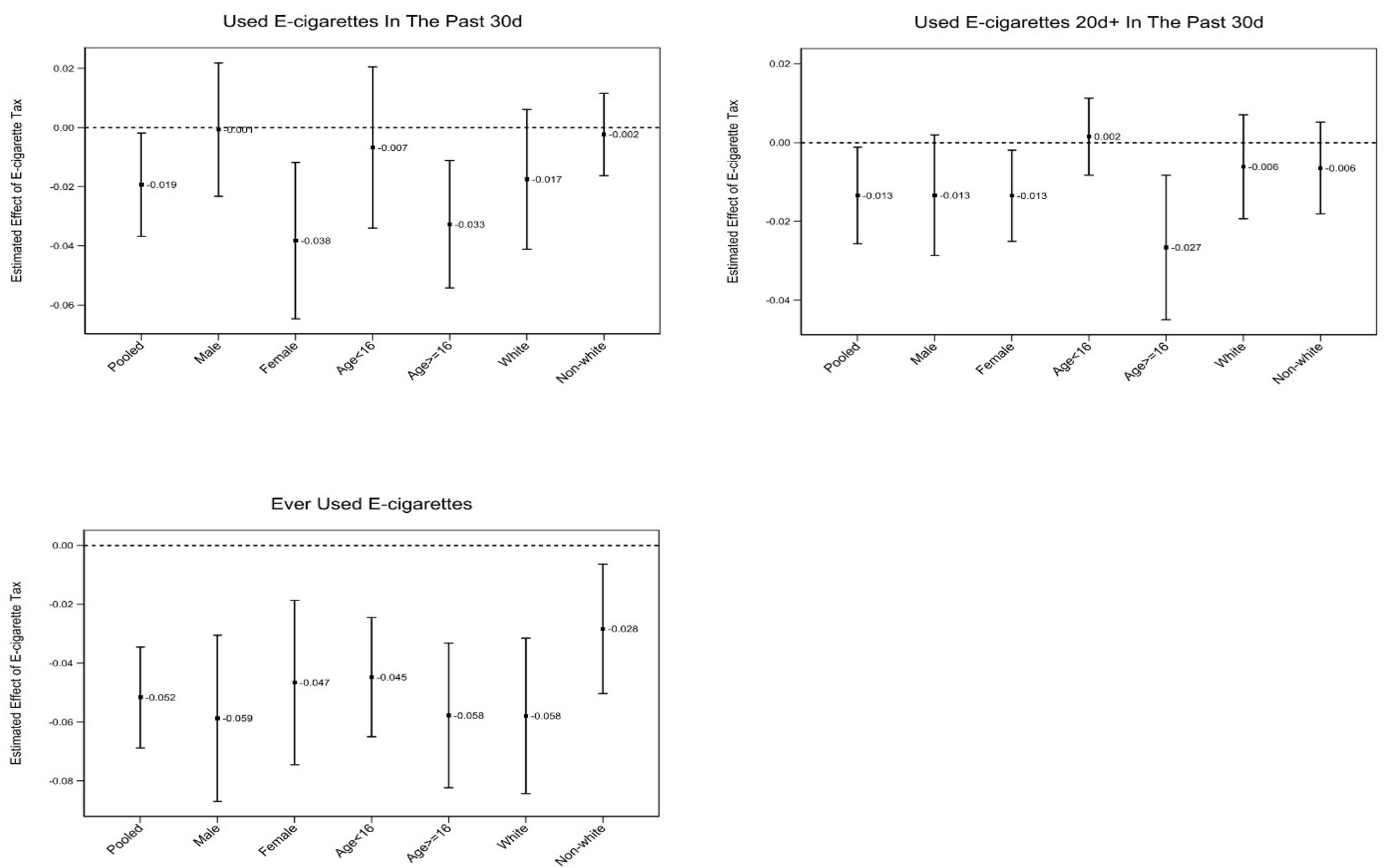

Notes: Estimated treatment effects are shown along with vertical bars depicting their $90 \%$ confidence intervals. 
Figure 3: Heterogeneity Check, Box-Whisker Graphs for Standardized ENDS Tax Rate (YRBSS)

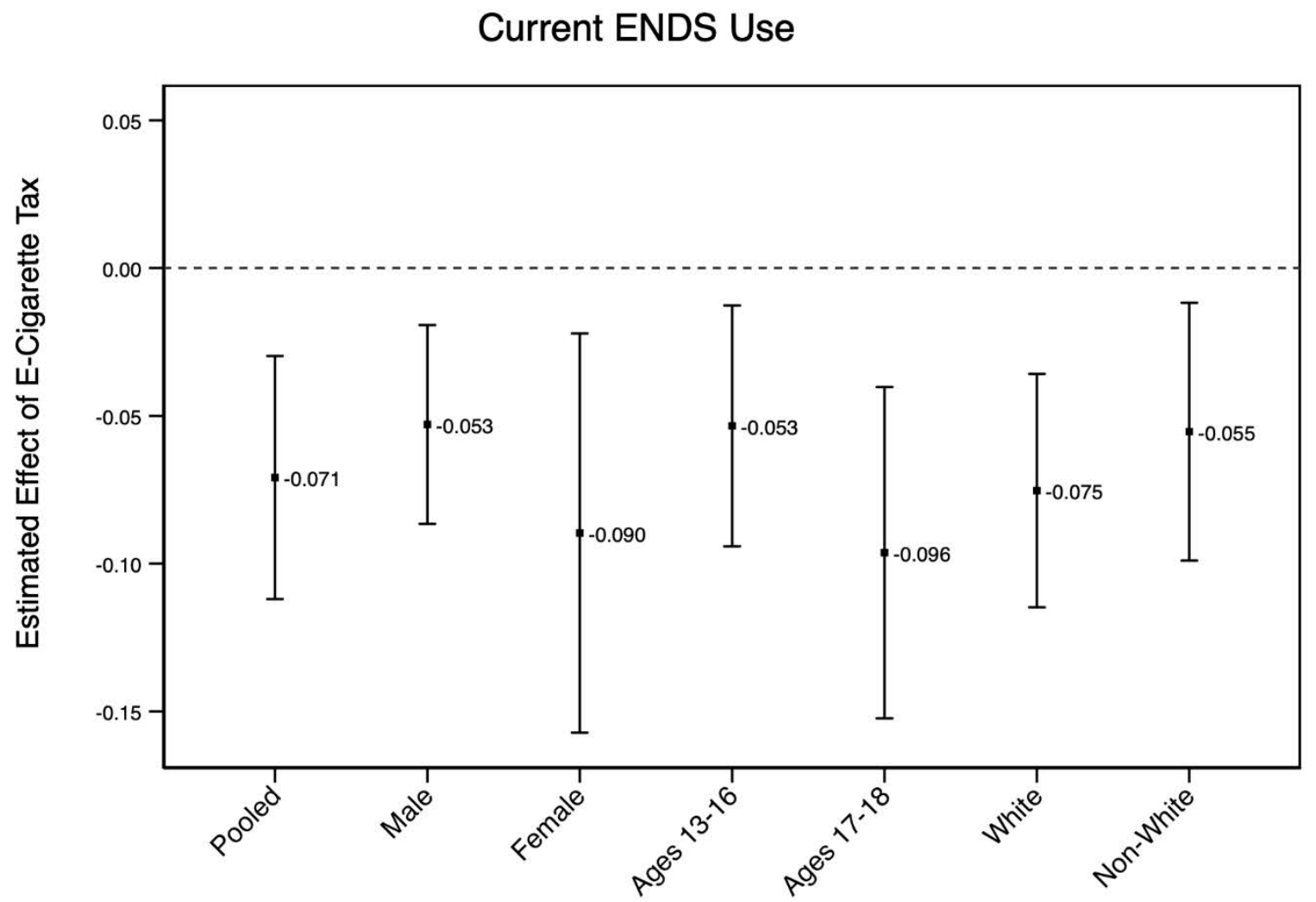

Notes: Estimated treatment effects are shown along with vertical bars depicting their $90 \%$ confidence intervals. 
Figure 4: Heterogeneity Check, Box-Whisker Graphs for Standardized ENDS Tax Rate (MTF)

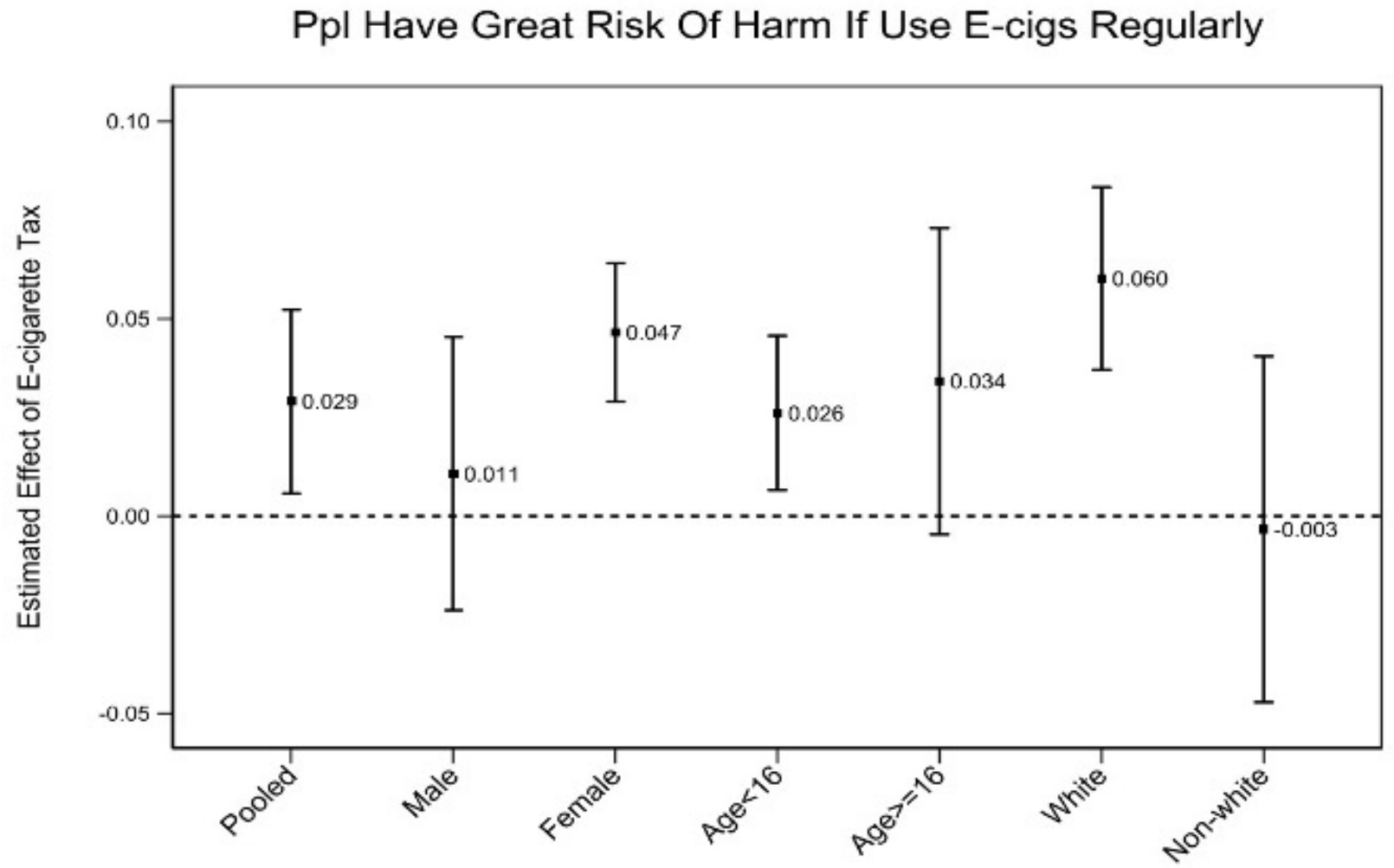

Notes: Estimated treatment effects are shown along with vertical bars depicting their $90 \%$ confidence intervals. 
Figure 5: Heterogeneity Check, Box-Whisker Graphs for Standardized ENDS Tax Rate (YRBSS)
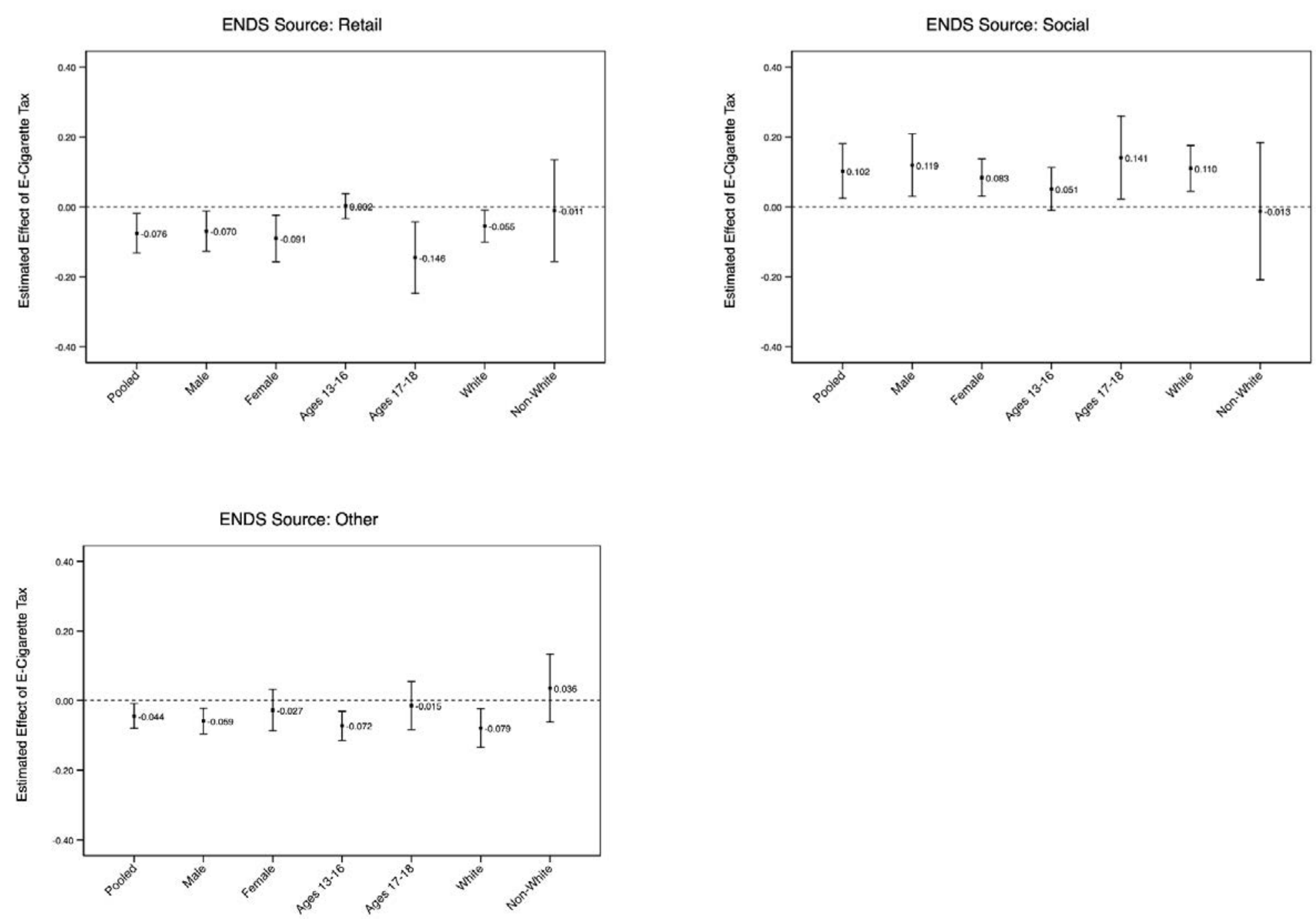
Figure 6: Heterogeneity Check, Box-Whisker Graphs for Standardized ENDS Tax Rate (MTF)
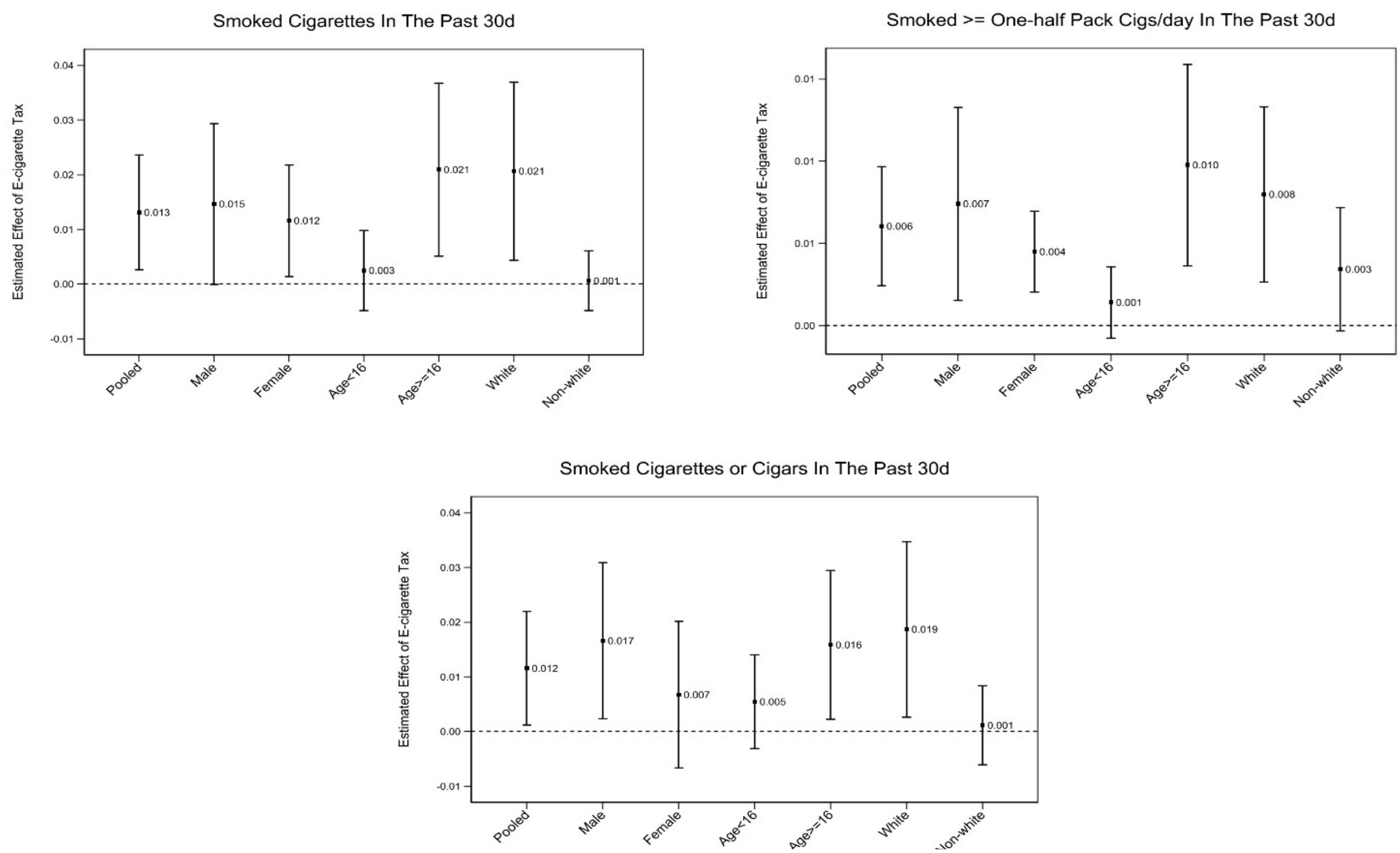

Notes: Estimated treatment effects are shown along with vertical bars depicting their $90 \%$ confidence intervals. 
Online Appendix Table 1: Unweighted Descriptive Statistics, 2014-2019 (MTF); 2015-2019 (YRBSS)

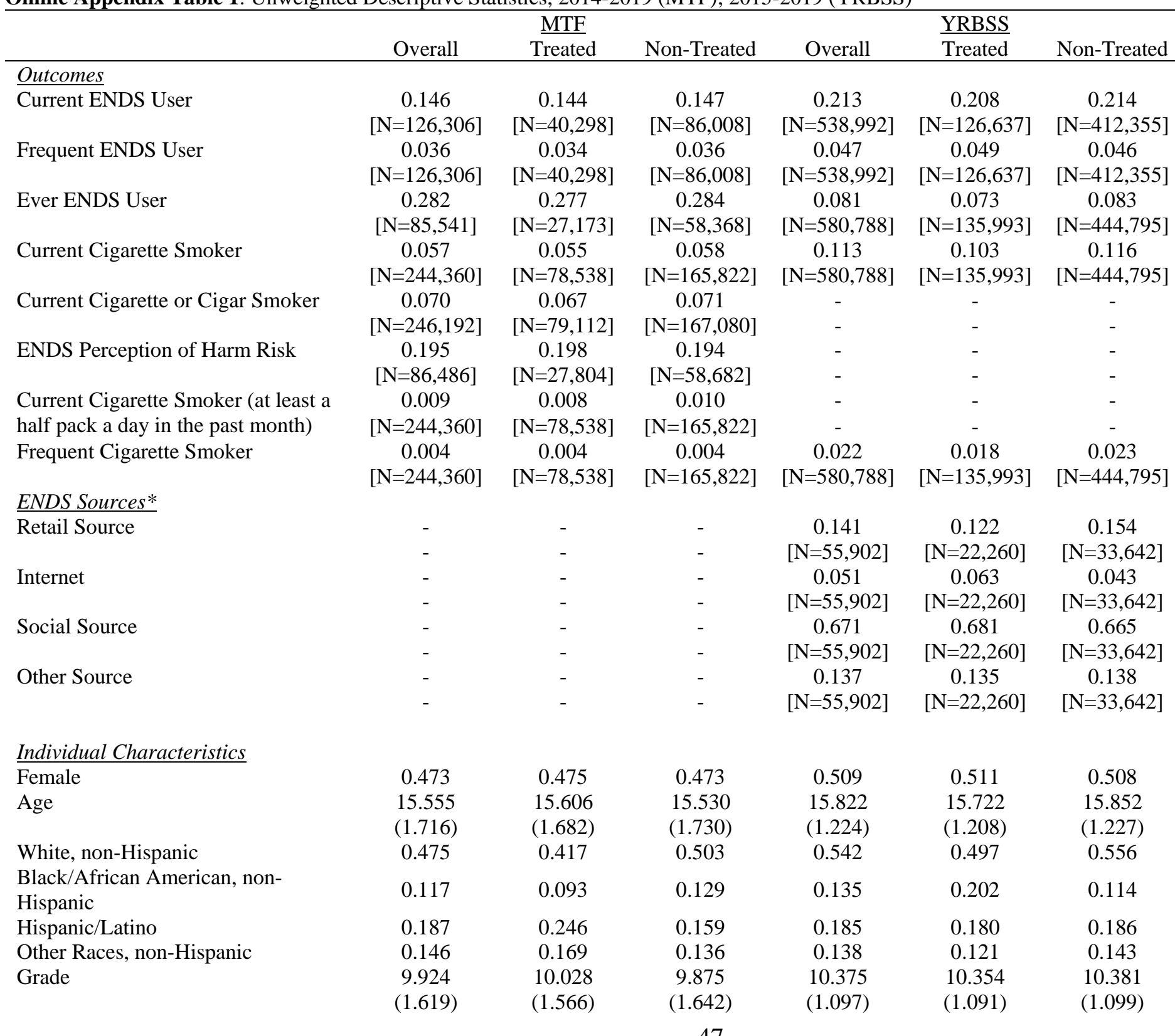


Policy and Economic Covariates ENDS Tax Rate per ml (2019 \$)

Cigarette Tax Rate per Pack (2019 \$)

\begin{tabular}{cccccc}
0.167 & 0.519 & - & 0.057 & 0.247 & - \\
$(0.489)$ & $(0.748)$ & - & $(0.199)$ & $(0.352)$ & - \\
3.017 & 3.164 & 2.947 & 3.211 & 3.054 & 3.258 \\
$(1.404)$ & $(1.461)$ & $(1.370)$ & $(1.134)$ & $(0.696)$ & $(1.232)$ \\
0.288 & 0.233 & 0.314 & 0.281 & 0.168 & 0.315 \\
$(0.261)$ & $(0.157)$ & $(0.294)$ & $(0.253)$ & $(0.163)$ & $(0.265)$ \\
0.154 & 0.279 & 0.095 & & & \\
& & & 0.094 & 0.076 & 0.100 \\
0.879 & 0.919 & 0.860 & 0.943 & 1.000 & 0.926 \\
& & & & & \\
0.815 & 0.882 & 0.784 & 0.886 & 0.961 & 0.863 \\
& & & & & \\
0.247 & 0.408 & 0.170 & 0.244 & 0.240 & 0.245 \\
0.130 & 0.194 & 0.100 & 0.103 & 0.041 & 0.121 \\
0.554 & 0.743 & 0.465 & 0.794 & 0.860 & 0.774 \\
0.961 & 0.974 & 0.954 & 0.988 & 0.994 & 0.986 \\
4.795 & 5.187 & 4.610 & 4.223 & 4.302 & 4.199 \\
$(1.511)$ & $(1.672)$ & $(1.391)$ & $(1.008)$ & $(0.462)$ & $(1.121)$ \\
13.937 & 14.102 & 13.860 & 11.101 & 9.597 & 11.556 \\
$(5.096)$ & $(4.884)$ & $(5.192)$ & $(3.061)$ & $(2.922)$ & $(2.955)$ \\
& & & & & \\
\hline 254,516 & 81,823 & 172,693 & 600,877 & 139,509 & 461,368 \\
\hline
\end{tabular}

Beer Tax Rate (2019 \$)

Tobacco 21 Percent Population

Coverage

ENDS Minimum Legal Sale Age

$(0 / 1)$

Indoor Smoking Restrictions Percent

Population Coverage

Indoor ENDS Restrictions Percent

Population Coverage

Recreational Marijuana Laws (0/1)

Medical Marijuana Laws (0/1)

Vertical License Law (0/1)

Unemployment Rate

Poverty Rates

he MTF data,

Notes: Means and standard deviations (in parenthesis) are reported. Since state/county-level information is available in the
policy/economic controls are at the county level except for beer taxes, marijuana laws, and vertical ID laws in which we only have state-level data. Since county information is not available in the national / state YRBSS, available county-level information is population-weighted to the state level.

* ENDS Sources are only for the years 2017-2019 and are conditional on an individual being a current ENDS user. 
Online Appendix Table 2: Sensitivity Analysis, Marginal Effects from Probit Modeling

Panel A: Effects of ENDS Tax on ENDS Use and ENDS Perceived Risk

\begin{tabular}{|c|c|c|c|c|c|}
\hline Outcome & Current ENDS User & Regular ENDS User & Ever Use ENDS & Current ENDS User & ENDS Perceived Risk \\
\hline \multirow{4}{*}{$\begin{array}{l}\text { ENDS Tax Rate per } \\
\text { ml }(2019 \$)\end{array}$} & -0.013 & -0.008 & $-0.048 * * *$ & $-0.061 * * *$ & $0.026 *$ \\
\hline & $(0.010)$ & $(0.005)$ & $(0.010)$ & $(0.024)$ & $(0.013)$ \\
\hline & {$[-0.034,0.007]$} & {$[-0.018,0.002]$} & {$[-0.068,-0.028]$} & {$[-0.108,-0.015]$} & {$[0.001,0.050]$} \\
\hline & $<0.195>$ & $<0.134>$ & $<0.000>$ & $<0.010>$ & $<0.041>$ \\
\hline \multirow{4}{*}{$\begin{array}{l}\text { Cigarette Tax Rate } \\
\text { per Pack (2019 \$) }\end{array}$} & -0.008 & 0.005 & 0.011 & 0.029 & -0.003 \\
\hline & $(0.009)$ & $(0.004)$ & $(0.008)$ & $(0.025)$ & $(0.007)$ \\
\hline & {$[-0.026,0.009]$} & {$[-0.003,0.014]$} & {$[-0.005,0.027]$} & {$[-0.020,0.079]$} & {$[-0.016,0.010]$} \\
\hline & $<0.353>$ & $<0.228>$ & $<0.175>$ & $<0.241>$ & $<0.636>$ \\
\hline Data & MTF & MTF & MTF & YRBSS & MTF \\
\hline Years & 2014-2019 & 2014-2019 & 2015-2019 & 2015-2019 & 2014-2018 \\
\hline $\mathrm{N}$ & 126,306 & 126,306 & 85,541 & 538,992 & 86,486 \\
\hline $\begin{array}{l}\text { Dependent Variable } \\
\text { Mean }\end{array}$ & 0.152 & 0.038 & 0.287 & 0.213 & 0.192 \\
\hline
\end{tabular}

Panel B: Effects of ENDS Tax on ENDS Sources and Combustible Tobacco Product Use

\begin{tabular}{|c|c|c|c|c|c|c|}
\hline Outcome & Retail Source & Social Source & Other Source & $\begin{array}{c}\text { Current Cigarette } \\
\text { Use }\end{array}$ & $\begin{array}{c}\text { Current Cigarette } \\
\text { Use (half pack a } \\
\text { day) }\end{array}$ & $\begin{array}{c}\text { Current Cigarette } \\
\text { or Cigar Use }\end{array}$ \\
\hline \multirow{4}{*}{$\begin{array}{l}\text { ENDS Tax Rate per } \\
\text { ml (2019 \$) }\end{array}$} & $-0.069 *$ & 0.099* & -0.034 & 0.011 & $0.007 * *$ & 0.009 \\
\hline & $(0.032)$ & $(0.045)$ & $(0.022)$ & $(0.008)$ & $(0.002)$ & $(0.008)$ \\
\hline & {$[-0.130,-0.007]$} & {$[0.011,0.187]$} & {$[-0.077,0.008]$} & {$[-0.004,0.026]$} & {$[0.002,0.012]$} & {$[-0.006,0.024]$} \\
\hline & $<0.030>$ & $<0.027>$ & $<0.113>$ & $<0.145>$ & $<0.006>$ & $<0.233>$ \\
\hline \multirow{4}{*}{$\begin{array}{l}\text { Cigarette Tax Rate } \\
\text { per Pack (2019 \$) }\end{array}$} & $0.069 *$ & $-0.103^{*}$ & 0.014 & 0.002 & -0.002 & 0.002 \\
\hline & $(0.029)$ & $(0.047)$ & $(0.022)$ & $(0.006)$ & $(0.002)$ & $(0.007)$ \\
\hline & {$[0.012,0.127]$} & {$[-0.195,-0.009]$} & {$[-0.029,0.057]$} & {$[-0.009,0.014]$} & {$[-0.006,0.002]$} & {$[-0.013,0.016]$} \\
\hline & $<0.018>$ & $<0.031>$ & $<0.526>$ & $<0.7>$ & $<0.326>$ & $<0.829>$ \\
\hline Data & YRBSS & YRBSS & YRBSS & MTF & MTF & MTF \\
\hline Years & 2017-2019 & 2017-2019 & 2017-2019 & 2014-2019 & 2014-2019 & 2014-2019 \\
\hline $\mathrm{N}$ & 55,902 & 55,902 & 55,902 & 244,360 & 244,360 & 246,192 \\
\hline $\begin{array}{l}\text { Dependent Variable } \\
\text { Mean }\end{array}$ & 0.185 & 0.627 & 0.145 & 0.066 & 0.012 & 0.080 \\
\hline
\end{tabular}

$+\mathrm{p}<0.10, * \mathrm{p}<0.05, * * \mathrm{p}<0.01, * * * \mathrm{p}<0.001$

Notes: All MTF models include tax jurisdiction fixed-effects, year-by-quarter fixed-effects, and each of the individual controls and policy/economic covariates listed in Table 2. All YRBSS models include state fixed-effects, year fixed-effects, and each of the individual controls and policy/economic covariates listed in Table 2. Regressions are weighted, standard errors are corrected for clustering at the state level, 95\% confidence intervals are shown in [ ] and p-values are shown in $<>$. 
Online Appendix Table 3: Sensitivity Analysis, Marginal Effects from Multinominal Logit Modeling

\begin{tabular}{|c|c|c|c|c|c|}
\hline Outcome & $\begin{array}{l}\text { No Current } \\
\text { ENDS Use }\end{array}$ & Retail Source & Social Source & Internet Source & Other Source \\
\hline \multirow[t]{2}{*}{ ml (2019 \$) } & $(0.016)$ & $(0.007)$ & $(0.009)$ & $(0.003)$ & $(0.005)$ \\
\hline & $<0.059>$ & $<0.026>$ & $<0.506>$ & $<0.465>$ & $<0.025>$ \\
\hline Cigarette Tax Rate & 0.014 & $0.013+$ & $-0.027 * *$ & -0.001 & 0.0003 \\
\hline per Pack (2019 \$) & $(0.016)$ & $(0.007)$ & $(0.009)$ & $(0.004)$ & $(0.005)$ \\
\hline Data & YRBSS & YRBSS & YRBSS & YRBSS & YRBSS \\
\hline Years & 2017-2019 & 2017-2019 & 2017-2019 & 2017-2019 & 2017-2019 \\
\hline $\mathrm{N}$ & 265,868 & 265,868 & 265,868 & 265,868 & 265,868 \\
\hline Dependent Variable Mean & 0.814 & 0.034 & 0.117 & 0.008 & 0.027 \\
\hline
\end{tabular}

Notes: All YRBSS models include state fixed effects, year fixed effects, and each of the individual controls and policy/economic covariates listed in Table 2. Regressions are weighted, standard errors are corrected for clustering at the state level, 95\% confidence intervals are shown in [ ] and p-values are shown in $<>$. 
Online Appendix Table 4: Sensitivity Analysis, Alternative Controls

Panel A: Effects of ENDS Tax on ENDS Use and ENDS Perceived Risk

\begin{tabular}{|c|c|c|c|c|c|}
\hline Outcome & Current ENDS User & Regular ENDS User & Ever Use ENDS & Current ENDS User & ENDS Perceived Risk \\
\hline \multirow[t]{3}{*}{ Baseline (Table 3) } & $-0.019+$ & $-0.013+$ & $-0.052 * * *$ & $-0.071^{* *}$ & $0.029 *$ \\
\hline & $(0.010)$ & $(0.007)$ & $(0.010)$ & $(0.025)$ & $(0.014)$ \\
\hline & {$[126,306]$} & {$[126,306]$} & {$[85,541]$} & {$[538,992]$} & {$[86,486]$} \\
\hline \multirow[t]{3}{*}{ Extra Controls } & -0.017 & $-0.018 * *$ & $-0.055 * * *$ & $-0.058 *$ & $0.030 *$ \\
\hline & $(0.011)$ & $(0.006)$ & $(0.010)$ & $(0.024)$ & $(0.014)$ \\
\hline & {$[-0.039,0.005]$} & {$[-0.031,-0.006]$} & {$[-0.075,-0.034]$} & {$[-0.106,-0.010]$} & {$[0.001,0.059]$} \\
\hline Add Little Cigar & -0.006 & $-0.016 *$ & $-0.058 * * *$ & $-0.066 *$ & $0.044 *$ \\
\hline \multirow[t]{2}{*}{ Tax Variables } & $(0.009)$ & $(0.007)$ & $(0.012)$ & $(0.030)$ & $(0.017)$ \\
\hline & {$[-0.025,0.012]$} & {$[-0.030,-0.002]$} & {$[-0.083,-0.034]$} & {$[-0.126,-0.005]$} & {$[0.010,0.079]$} \\
\hline Add Large Cigar & -0.007 & -0.005 & $-0.034+$ & $-0.092 * *$ & 0.025 \\
\hline \multirow[t]{2}{*}{ Tax Variables } & $(0.014)$ & $(0.008)$ & $(0.020)$ & $(0.032)$ & $(0.019)$ \\
\hline & {$[-0.035,0.021]$} & {$[-0.021,0.012]$} & {$[-0.074,0.006]$} & {$[-0.156,-0.028]$} & {$[-0.012,0.063]$} \\
\hline MTF Extra Individual- & $-0.021+$ & $-0.015 *$ & $-0.060 * * *$ & NA & $0.033^{*}$ \\
\hline \multirow[t]{2}{*}{ Level Control Variables } & $(0.012)$ & $(0.007)$ & $(0.010)$ & -- & $(0.014)$ \\
\hline & {$[-0.044,0.002]$} & {$[-0.030,-0.001]$} & {$[-0.081,-0.039]$} & & {$[0.004,0.061]$} \\
\hline Data & MTF & MTF & MTF & YRBSS & MTF \\
\hline
\end{tabular}

Panel B: Effects of ENDS Tax on ENDS Sources and Combustible Tobacco Product Use

\begin{tabular}{|c|c|c|c|c|c|c|}
\hline Outcome & Retail Source & Social Source & Other Source & $\begin{array}{c}\text { Current Cigarette } \\
\text { Use }\end{array}$ & $\begin{array}{c}\text { Current Cigarette } \\
\text { Use (half pack a } \\
\text { day) }\end{array}$ & $\begin{array}{l}\text { Current Cigarette } \\
\text { or Cigar Use }\end{array}$ \\
\hline \multirow[t]{3}{*}{ Baseline (Table 3) } & $-0.076 *$ & $0.101^{*}$ & $-0.044^{*}$ & $0.013^{*}$ & $0.006 * *$ & $0.012+$ \\
\hline & $(0.034)$ & $(0.046)$ & $(0.021)$ & $(0.006)$ & $(0.002)$ & $(0.006)$ \\
\hline & {$[55,902]$} & {$[55,902]$} & {$[55,902]$} & {$[244,360]$} & {$[244,360]$} & {$[246,192]$} \\
\hline \multirow[t]{3}{*}{ Extra Controls } & $-0.077+$ & $0.126^{*}$ & $-0.061 *$ & $0.013+$ & $0.008 *$ & $0.012+$ \\
\hline & $(0.039)$ & $(0.061)$ & $(0.026)$ & $(0.007)$ & $(0.003)$ & $(0.007)$ \\
\hline & {$[-0.156,0.003]$} & {$[0.004,0.248]$} & {$[-0.113,-0.009]$} & {$[-0.001,0.027]$} & {$[0.002,0.014]$} & {$[-0.002,0.026]$} \\
\hline Add Little Cigar & -0.042 & 0.033 & -0.020 & -0.003 & 0.002 & -0.001 \\
\hline \multirow{2}{*}{ Tax Variables } & $(0.036)$ & $(0.031)$ & $(0.018)$ & $(0.005)$ & $(0.003)$ & $(0.005)$ \\
\hline & {$[-0.114,0.029]$} & {$[-0.030,0.097]$} & {$[-0.056,0.017]$} & {$[-0.012,0.007]$} & {$[-0.004,0.008]$} & {$[-0.010,0.008]$} \\
\hline Add Large Cigar & $-0.399 *$ & $0.672 *$ & -0.128 & $0.018 *$ & $0.008 *$ & $0.014^{*}$ \\
\hline \multirow[t]{2}{*}{ Tax Variables } & $(0.195)$ & $(0.291)$ & $(0.087)$ & $(0.007)$ & $(0.003)$ & $(0.007)$ \\
\hline & {$[-0.791,-0.007]$} & {$[-0.085,1.259]$} & {$[-0.303,0.047]$} & {$[0.003,0.033]$} & {$[0.002,0.015]$} & {$[0.001,0.027]$} \\
\hline MTF Extra Individual- & NA & NA & NA & $0.008+$ & $0.005^{*}$ & 0.007 \\
\hline \multirow[t]{2}{*}{ Level Control Variables } & -- & -- & -- & $(0.005)$ & $(0.002)$ & $(0.005)$ \\
\hline & & & & {$[-0.001,0.018]$} & {$[0.001,0.009]$} & {$[-0.004,0.017]$} \\
\hline Data & YRBSS & YRBSS & YRBSS & MTF & MTF & MTF \\
\hline
\end{tabular}


$+p<0.10, * p<0.05, * * p<0.01, * * * p<0.001$

Notes: Estimated coefficients and standard errors for ENDS tax rate per ml (2019 \$) reported. All MTF models include tax jurisdiction fixed-effects, year-by-quarter fixed-effects, and each of the individual controls and policy/economic covariates listed in Table 2. All YRBSS models include state fixed-effects, year fixed-effects, and each of the individual controls and policy/economic covariates listed in Table 2. "Extra" controls are ENDS licensure laws, packaging laws, and public school (K-12) smoke-free and vape-free laws. Cigar tax controls are excise and ad valorem taxes. MTF extra individual-level controls are parental education and urban/rural status. Regressions are weighted and standard errors are corrected for clustering at the state level. 
Online Appendix Table 5: Sensitivity Analysis, Alternative Samples

Panel A: Effects of ENDS Tax on ENDS Use and ENDS Perceived Risk

\begin{tabular}{|c|c|c|c|c|c|}
\hline Outcome & Current ENDS User & Regular ENDS User & Ever Use ENDS & Current ENDS User & ENDS Perceived Risk \\
\hline \multirow[t]{3}{*}{ Baseline (Table 3) } & $-0.019+$ & $-0.013+$ & $-0.052 * * *$ & $-0.071 * *$ & $0.029 *$ \\
\hline & $(0.010)$ & $(0.007)$ & $(0.010)$ & $(0.025)$ & $(0.014)$ \\
\hline & {$[126,306]$} & {$[126,306]$} & {$[85,541]$} & {$[538,992]$} & {$[86,486]$} \\
\hline Drop States w/ Same- & $-0.031 * *$ & $-0.021 * * *$ & $-0.053 * * *$ & $-0.070 * *$ & 0.018 \\
\hline \multirow[t]{2}{*}{ Period Policy Changes } & $(0.009)$ & $(0.005)$ & $(0.010)$ & $(0.025)$ & $(0.016)$ \\
\hline & {$[118,727]$} & {$[118,727]$} & {$[80,254]$} & {$[528,955]$} & {$[81,491]$} \\
\hline Retaining Irregularly & $-0.020+$ & $-0.013+$ & $-0.053 * * *$ & NA & 0.028* \\
\hline \multirow[t]{2}{*}{ Surveyed States } & $(0.010)$ & $(0.007)$ & $(0.010)$ & -- & $(0.013)$ \\
\hline & {$[130,183]$} & {$[130,183]$} & {$[87,833]$} & & {$[89,508]$} \\
\hline Data & MTF & MTF & MTF & YRBSS & MTF \\
\hline
\end{tabular}

Panel B: Effects of ENDS Tax on ENDS Sources and Combustible Tobacco Product Use

\begin{tabular}{|c|c|c|c|c|c|c|}
\hline Outcome & Retail Source & Social Source & Other Source & $\begin{array}{c}\text { Current Cigarette } \\
\text { Use }\end{array}$ & $\begin{array}{c}\text { Current Cigarette } \\
\text { Use (half pack a } \\
\text { day) }\end{array}$ & $\begin{array}{l}\text { Current Cigarette } \\
\text { or Cigar Use }\end{array}$ \\
\hline \multirow[t]{3}{*}{ Baseline (Table 3) } & $-0.076 *$ & $0.101^{*}$ & $-0.044^{*}$ & $0.013^{*}$ & $0.006 * *$ & $0.012+$ \\
\hline & $(0.034)$ & $(0.046)$ & $(0.021)$ & $(0.006)$ & $(0.002)$ & $(0.006)$ \\
\hline & {$[55,902]$} & {$[55,902]$} & {$[55,902]$} & {$[244,360]$} & {$[244,360]$} & {$[246,192]$} \\
\hline Drop States w/ Same-Period & $-0.060+$ & $0.090+$ & $-0.047 *$ & 0.012 & $0.007 *$ & 0.009 \\
\hline \multirow[t]{2}{*}{ Policy Changes } & $(0.035)$ & $(0.048)$ & $(0.022)$ & $(0.008)$ & $(0.003)$ & $(0.007)$ \\
\hline & {$[54,816]$} & {$[54,816]$} & {$[54,816]$} & {$[229,823]$} & {$[229,823]$} & {$[231,588]$} \\
\hline Retaining Irregularly Surveyed & NA & NA & NA & $0.013^{*}$ & $0.006 * *$ & $0.011+$ \\
\hline \multirow[t]{2}{*}{ States } & -- & -- & -- & $(0.006)$ & $(0.002)$ & $(0.006)$ \\
\hline & & & & {$[252,117]$} & {$[252,117]$} & {$[254,020]$} \\
\hline Longer Time Horizon for Cig. & NA & NA & NA & $0.018 *$ & $0.011 * * *$ & $0.018 * *$ \\
\hline \multirow[t]{2}{*}{ Outcomes } & -- & -- & -- & $(0.007)$ & $(0.003)$ & $(0.006)$ \\
\hline & & & & {$[369,764]$} & {$[369,764]$} & {$[371,596]$} \\
\hline Data & YRBSS & YRBSS & YRBSS & MTF & MTF & MTF \\
\hline
\end{tabular}

Notes: Estimated coefficients and standard errors for ENDS tax rate per ml (2019 \$) reported. All MTF models include tax jurisdiction fixed-effects, year-by-quarter fixed-effects, and each of the individual controls and policy/economic covariates listed in Table 2. All YRBSS models include state fixed-effects, year fixed-effects, and each of the individual controls and policy/economic covariates listed in Table 2. Regressions are weighted and standard errors are corrected for clustering at the state level. 
Online Appendix Table 6: Sensitivity Analysis, Unweighted

Panel A: Effects of ENDS Tax on ENDS Use and ENDS Perceived Risk

\begin{tabular}{|c|c|c|c|c|c|}
\hline Outcome & Current ENDS User & Regular ENDS User & Ever Use ENDS & Current ENDS User & ENDS Perceived Risk \\
\hline \multirow{4}{*}{$\begin{array}{l}\text { ENDS Tax Rate per } \\
\text { ml (2019 \$) }\end{array}$} & -0.016 & -0.011 & $-0.041^{* *}$ & $-0.064^{*}$ & $0.019+$ \\
\hline & $(0.014)$ & $(0.008)$ & $(0.012)$ & $(0.029)$ & $(0.011)$ \\
\hline & {$[-0.045,0.012]$} & {$[-0.028,0.005]$} & {$[-0.065,-0.016]$} & {$[-0.123,-0.005]$} & {$[-0.003,0.042]$} \\
\hline & $<0.247>$ & $<0.178>$ & $<0.002>$ & $<0.033>$ & $<0.093>$ \\
\hline \multirow{4}{*}{$\begin{array}{l}\text { Cigarette Tax Rate } \\
\text { per Pack (2019 \$) }\end{array}$} & -0.004 & 0.005 & 0.005 & 0.030 & -0.002 \\
\hline & $(0.008)$ & $(0.005)$ & $(0.006)$ & $(0.032)$ & $(0.006)$ \\
\hline & {$[-0.021,0.013]$} & {$[-0.004,0.015]$} & {$[-0.008,0.017]$} & {$[-0.035,0.095]$} & {$[-0.013,0.010]$} \\
\hline & $<0.645>$ & $<0.287>$ & $<0.452>$ & $<0.361>$ & $<0.785>$ \\
\hline Data & MTF & MTF & MTF & YRBSS & MTF \\
\hline Years & 2014-2019 & 2014-2019 & 2015-2019 & 2015-2019 & 2014-2018 \\
\hline $\mathrm{N}$ & 126,306 & 126,306 & 85,541 & 538,992 & 86,486 \\
\hline $\begin{array}{l}\text { Dependent Variable } \\
\text { Mean }\end{array}$ & 0.146 & 0.036 & 0.282 & 0.213 & 0.195 \\
\hline
\end{tabular}

Panel B: Effects of ENDS Tax on ENDS Sources and Combustible Tobacco Product Use

\begin{tabular}{|c|c|c|c|c|c|c|}
\hline Outcome & Retail Source & Social Source & Other Source & $\begin{array}{c}\text { Current Cigarette } \\
\text { Use }\end{array}$ & $\begin{array}{c}\text { Current Cigarette } \\
\text { Use (half pack a } \\
\text { day) }\end{array}$ & $\begin{array}{c}\text { Current Cigarette } \\
\text { or Cigar Use }\end{array}$ \\
\hline \multirow{4}{*}{$\begin{array}{l}\text { ENDS Tax Rate per } \\
\text { ml (2019 \$) }\end{array}$} & -0.012 & -0.007 & -0.009 & $0.008^{*}$ & $0.005^{* * *}$ & $0.010^{* *}$ \\
\hline & $(0.018)$ & $(0.034)$ & $(0.024)$ & $(0.004)$ & $(0.001)$ & $(0.004)$ \\
\hline & {$[-0.049,0.025]$} & {$[-0.075,0.061]$} & {$[-0.057,0.038]$} & {$[0.001,0.016]$} & {$[0.003,0.007]$} & {$[0.003,0.017]$} \\
\hline & $<0.509>$ & $<0.834>$ & $<0.699>$ & $<0.024>$ & $<0.000>$ & $<0.008>$ \\
\hline \multirow{4}{*}{$\begin{array}{l}\text { Cigarette Tax Rate } \\
\text { per Pack (2019 \$) }\end{array}$} & $0.043^{*}$ & $-0.065+$ & 0.014 & -0.003 & $-0.003^{* *}$ & -0.007 \\
\hline & $(0.018)$ & $(0.033)$ & $(0.021)$ & $(0.004)$ & $(0.001)$ & $(0.005)$ \\
\hline & {$[0.007,0.079]$} & {$[-0.131,0.001]$} & {$[-0.029,0.057]$} & {$[-0.012,0.005]$} & {$[-0.004,-0.001]$} & {$[-0.016,0.003]$} \\
\hline & $<0.020>$ & $<0.054>$ & $<0.521>$ & $<0.438>$ & $<0.003>$ & $<0.166>$ \\
\hline Data & YRBSS & YRBSS & YRBSS & MTF & MTF & MTF \\
\hline Years & 2017-2019 & 2017-2019 & 2017-2019 & 2014-2019 & 2014-2019 & 2014-2019 \\
\hline $\mathrm{N}$ & 55,902 & 55,902 & 55,902 & 244,360 & 244,360 & 246,192 \\
\hline $\begin{array}{l}\text { Dependent Variable } \\
\text { Mean }\end{array}$ & 0.123 & 0.680 & 0.135 & 0.057 & 0.009 & 0.070 \\
\hline
\end{tabular}

$+\mathrm{p}<0.10, * \mathrm{p}<0.05, * * \mathrm{p}<0.01, * * * \mathrm{p}<0.001$

Notes: All MTF models include tax jurisdiction fixed-effects, year-by-quarter fixed-effects, and each of the individual controls and policy/economic covariates listed in Table 2. All YRBSS models include state fixed-effects, year fixed-effects, and each of the individual controls and policy/economic covariates listed in Table 2. Standard errors are corrected for clustering at the state level, 95\% confidence intervals are shown in [ ] and p-values are shown in $<>$. 
Online Appendix Table 7: Sensitivity Analysis, Any Vaping for Years 2017+

\begin{tabular}{lcc}
\hline Outcome & Current ENDS User & Regular ENDS User \\
\hline ENDS Tax Rate per ml $(2019 \$)$ & $-0.020^{*}$ & $-0.014^{*}$ \\
& $(0.008)$ & $(0.007)$ \\
& {$[-0.037,-0.004]$} & {$[-0.028,-0.001]$} \\
Cigarette Tax Rate per Pack $(2019 \$)$ & $<0.019>$ & $<0.038>$ \\
& -0.005 & $0.008+$ \\
& $(0.006)$ & $(0.004)$ \\
& {$[-0.017,0.008]$} & {$[-0.001,0.017]$} \\
Data & $<0.453>$ & $<0.069>$ \\
Years & MTF & MTF \\
\hline $\mathrm{N}$ & $2014-2019$ & $2014-2019$ \\
Dependent Variable Mean & 152,674 & 152,674 \\
\hline$+\mathrm{p}<0.10, * \mathrm{p}<0.05, * * \mathrm{p}<0.01, * * * \mathrm{p}<0.001$ & 0.162 & 0.043 \\
\hline $\mathrm{N}<\mathrm{All}$ MT & &
\end{tabular}

$+\mathrm{p}<0.10,{ }^{*} \mathrm{p}<0.05, * * \mathrm{p}<0.01, * * * \mathrm{p}<0.001$

Notes: All MTF models include tax jurisdiction fixed-effects, year-by-quarter fixed-effects, and each of the

individual controls and policy/economic covariates listed in Table 2. Regressions are weighted, standard errors are corrected for clustering at the state level, 95\% confidence intervals are shown in [ ] and p-values are shown in $<>$. 
Online Appendix Table 8: Sensitivity Analysis, Alternative Standard Error Adjustment

Panel A: Effects of ENDS Tax on ENDS Use and ENDS Perceived Risk

\begin{tabular}{|c|c|c|c|c|c|}
\hline Outcome & $\begin{array}{c}\text { Current ENDS } \\
\text { User } \\
\end{array}$ & $\begin{array}{c}\text { Regular ENDS } \\
\text { User } \\
\end{array}$ & $\begin{array}{c}\text { Ever } \\
\text { Use ENDS } \\
\end{array}$ & $\begin{array}{c}\text { Current ENDS } \\
\text { User } \\
\end{array}$ & $\begin{array}{c}\text { ENDS Perceived } \\
\text { Risk } \\
\end{array}$ \\
\hline Baseline (Table 3) & $-0.019+$ & $-0.013+$ & $-0.052 * * *$ & $-0.071 * *$ & $0.029 *$ \\
\hline With Wild Cluster Bootstrap & $-0.019+$ & $-0.013+$ & $-0.052 *$ & $-0.071^{*}$ & 0.029* \\
\hline With Holm-Bonferroni adjustment & -0.019 & -0.013 & $-0.052 * * *$ & $-0.071 * *$ & $0.029 *$ \\
\hline With sharpened two-stage adjustment & $-0.019+$ & $-0.013+$ & $-0.052 * * *$ & $-0.071 * *$ & $0.029 *$ \\
\hline Data & MTF & MTF & MTF & YRBSS & MTF \\
\hline Years & 2014-2019 & 2014-2019 & 2015-2019 & 2015-2019 & $2014-2018$ \\
\hline $\mathrm{N}$ & 126,306 & 126,306 & 85,541 & 538,992 & 86,486 \\
\hline
\end{tabular}

Panel B: Effects of ENDS Tax on ENDS Sources and Combustible Tobacco Product Use

\begin{tabular}{|c|c|c|c|c|c|c|}
\hline Outcome & Retail Source & Social Source & Other Source & $\begin{array}{c}\text { Current } \\
\text { Cigarette Use }\end{array}$ & $\begin{array}{c}\text { Current Cigarette } \\
\text { Use (half pack a } \\
\text { day) }\end{array}$ & $\begin{array}{c}\text { Current Cigarette or } \\
\text { Cigar Use }\end{array}$ \\
\hline Baseline (Table 3) & $-0.076^{*}$ & $0.102 *$ & $-0.044^{*}$ & $0.013^{*}$ & $0.006^{* *}$ & $0.012+$ \\
\hline With Wild Cluster Bootstrap & $-0.076+$ & $0.101+$ & -0.044 & $0.013 *$ & $0.006+$ & $0.012+$ \\
\hline With Holm-Bonferroni adjustment & -0.076 & 0.102 & $-0.044+$ & $0.013+$ & $0.006^{*}$ & $0.012+$ \\
\hline With sharpened two-stage adjustment & $-0.076+$ & $0.102+$ & $-0.044+$ & $0.013^{*}$ & $0.006 *$ & $0.012 *$ \\
\hline Data & YRBSS & YRBSS & YRBSS & MTF & MTF & MTF \\
\hline Years & 2017-2019 & 2017-2019 & $2017-2019$ & 2014-2019 & 2014-2019 & 2014-2019 \\
\hline $\mathrm{N}$ & 55,902 & 55,902 & 55,902 & 244,360 & 244,360 & 246,192 \\
\hline
\end{tabular}

$+\mathrm{p}<0.10,{ }^{*} \mathrm{p}<0.05,{ }^{* *} \mathrm{p}<0.01, * * * \mathrm{p}<0.001$

Notes: Estimated coefficients for ENDS tax rate per ml (2019 \$) reported. All MTF models include tax jurisdiction fixed-effects, year-by-quarter fixed-effects, and each of the individual controls and policy/economic covariates listed in Table 2. All YRBSS models include state fixed-effects, year fixed-effects, and each of the individual controls and policy/economic covariates listed in Table 2. See Benjamini, Krieger, and Yekutieli (2006) and Anderson (2008) for explanation of sharpened two-stage adjustment procedure. Standard errors are corrected for clustering at the state level and for the procedure described in the first column, 95\% confidence intervals are shown in [ ] and p-values are shown in $<>$. 


\section{Online Data Appendix:}

\section{$\underline{\text { MTF }}$}

In general, MTF uses six different questionnaire forms to survey $12^{\text {th }}$ graders and four different forms to survey $8^{\text {th }}$ and $10^{\text {th }}$ graders. Identical forms are used for both $8^{\text {th }}$ and $10^{\text {th }}$ graders. To reduce burden on respondents, not all questions are included in every form. For the outcome variables that we study, only cigarette use (IRN 00780) exists in all forms. Sample sizes for the other outcome variables are thus smaller by construction. The MTF variables are coded as follows.

- ENDS current and frequent use: Questions in MTF on youth use of ENDS have changed wordings over our study period, we thus use the following variables to collectively define youth use of ENDS: IRN33710, IRN33840, IRN34370, IRN35340, and IRN35160. In particular, we define youth as a current ENDS user if they used ENDS at least once in the past month and as a frequent ENDS user if they used ENDS in 20 or more days over the past 30 days. As a sensitivity analysis, starting in 2017 we also include questions IRN34260, IRN34290, IRN34320, IRN35190, and IRN35220 for any vaping, which could include THC and flavoring products.

- ENDS initiation: We define youth ENDS initiation via the survey question (IRN33960), which asks, "When (if ever) did you FIRST do each of the following things? Don't count anything you took because a doctor told you to. Try an ENDS, e-pen, etc." The answer responses are: "Grade 6 or below, Grade 7, Grade 8, Grade 9 (Freshman), Grade 10 (Sophomore), Grade 11 (Junior), Grade 12 (Senior), and Never." We define the ENDS initiation variable as an indicator, setting it equal to one if the answer matches youth 
current grade at the time of survey and zero if youth answered never. All other answer responses are coded as missing. IRN33960 entered the survey starting in year 2015.

- ENDS ever use: Like ENDS current and frequent use, we use the following variables to collectively define youth ever use of ENDS: IRN33830, IRN34230, IRN34240, IRN35140, and IRN35320. MTF included these questions starting in year 2015.

- Perceived risk of regular ENDS use being greatly risky: The indicator is set to one if youth believe that an individual is at great risk of harming themselves (physically or in other ways) if they use ENDS regularly and zero otherwise. The indicator is set to missing when youth did not provide a response to the question. MTF included this question (IRN33670) from 2014 to 2018. The question is not available in year 2019.

- Current and regular cigarette use: The relevant question (IRN 00780) asked is: "How frequently have you smoked cigarettes during the past 30 days?” Possible responses include: $1=$ "Not at all," 2="Less than one cigarette per day," 3="One to five cigarettes per day," 4="About one-half pack per day," 5="About one pack per day," 6="About one and one-half packs per day," and 7="Two packs or more per day" We define youth as a current traditional cigarette user if he/she used traditional cigarettes at least once in the past month, and we also use a separate outcome for if he/she used at least one-half pack of traditional cigarettes per day in the past month. IRN 00780 exists in the MTF for all years that we study.

- Current cigar or cigarette use: First, for the current cigar use variable we use three questions to collectively define this indicator: IRN33720, IRN33730, and IRN33740. Question wordings across the three variables are similar except that IRN33720 focuses on large cigars, IRN33730 focuses on flavored small cigars, and IRN33740 focuses on non- 
flavored small cigars. The question wording is: "During the LAST 30 DAYS, on how many days (if any) have you .... . . smoked large (flavored small, or regular small) cigars?” Possible responses include: 1="None" 2="1-2" 3="3-5" 4="6-9" 5="10-19" 6="20-30." Hence, we first create an indicator for each of the three cigar use types by setting it equal to 1 if youth used at least one day in the past month and 0 otherwise. Current cigar use is then the union of the three separate current cigar use indicators and is missing only if all three cigar variables are missing. Analogously, current cigar or cigarette use is the union of current cigar use and current cigarette use variables. Like the cigarette use variable, all cigar use variables exist in the MTF for all years that we study though only on some forms.

\section{$\underline{\text { YRBSS }}$}

The ordering of the questions preceding and following the current ENDS use have been the same between 2017-2019. However, ENDS source questions were only asked starting in 2017. The prompt before the ENDS questions has changed marginally each year in a way that we believe signals to the youth that the question is specifically about nicotine vaping products, since the brand names are only for nicotine vapes.

2015: The next two questions ask about electronic vapor products, such as blu, NJOY, or Starbuzz. Electronic vapor products include e-cigarettes, e-cigars, e-pipes, vape pipes, vaping pens, ehookahs, and hookah pens. 
2017: The next three questions ask about electronic vapor products, such as blu, NJOY, Vuse, MarkTen, Logic, Vapin Plus, eGo, and Halo. Electronic vapor products include ecigarettes, ecigars, e-pipes, vape pipes, vaping pens, e-hookahs, and hookah pens.

2019: The next three questions ask about electronic vapor products, such as JUUL, Vuse, MarkTen, and blu. Electronic vapor products include e-cigarettes, vapes, vape pens, e-cigars, ehookahs, hookah pens, and mods.

34. Have you ever used an electronic vapor product?
A. Yes
B. No

35. During the past 30 days, on how many days did you use an electronic vapor product?
A. 0 days
B. 1 or 2 days
C. 3 to 5 days
D. 6 to 9 days
E. 10 to 19 days
F. 20 to 29 days
G. All 30 days

36. During the past 30 days, how did you usually get your electronic vapor products? (Select only one response.) 
A. I did not use any electronic vapor products during the past 30 days

B. I got or bought them from a friend, family member, or someone else

C. I bought them myself in a vape shop or tobacco shop

D. I bought them myself in a convenience store, supermarket, discount store, or gas station

E. I bought them myself at a mall or shopping center kiosk or stand

F. I bought them myself on the Internet, such as from a product website, vape store website, or other website like eBay, Amazon, Facebook Marketplace, or Craigslist

G. I took them from a store or another person

H. I got them in some other way

We categorize B as retail-purchased, C as internet purchased, and D, E, and F as social sourced, and $\mathrm{G}$ and $\mathrm{H}$ as other.

\section{$\underline{\text { Policy and economic covariates }}$}

The following policy and economic covariates are used, averaged across the first and second quarters of each year to match the data collection time-frames for both MTF and YRBSS surveys. Data is used at the county-level for MTF analyses, unless otherwise stated to be only available at the state level. Local data is population-weighted to the state level for all YRBSS analyses, given the lack of county geocodes in this data.

- Tobacco laws:

1. Standardized ENDS taxes per fluid ml, described in detail in Cotti et al. (2021). 
2. Cigarette taxes are the federal cigarette excise tax (\$1.01 over the study period) + state cigarette excise tax (from the CDC State System) ${ }^{32}+$ local cigarette excise tax (from the American Non-Smokers Rights Foundation). ${ }^{33}$

3. ENDS minimum legal sales age laws, as obtained from Pesko and Currie (2019).

4. Percent of residents living in areas with a state or local tobacco 21 law, derived from state laws and local law information. ${ }^{34}$

5. Indoor air laws: We follow prior work (Cooper and Pesko 2017) in generating a smoke-free air law index based on American Non-Smokers Rights Foundation data $^{33}$ on states and jurisdictions banning smoking in restaurants, bars, and private workplaces. Specifically, we use the percent of the population covered under these laws in each state, weighing laws applied to bars, restaurants, and private workplaces equally, and treating partial bans (e.g., separate smoking areas) with half the weight of a full ban. We use the same method to create a parallel vapefree air law index.

6. Sensitivity Analysis: State-level ENDS retail licensure requirements to sell ENDS from the CDC State System. ${ }^{32}$

7. Sensitivity Analysis: State-level ENDS and other tobacco smoke-free campus laws for K-12 public schools from the CDC State System. ${ }^{32}$

\footnotetext{
${ }^{32}$ CDC State System. Available at: https://www.cdc.gov/statesystem/index.html (last accessed April 13 ${ }^{\text {th }}$, 2021).

${ }_{33}$ American Non-Smokers Rights Foundation. ANRF Deliverables for GSU 2019-12-31 (Pesko).zip. Maggie Hopkins <Maggie.Hopkins@no-smoke.org> (last accessed January 31 ${ }^{\text {st }}$, 2020).

${ }^{34}$ Preventing Tobacco Addiction Foundation. US Communities with Tobacco21 Ordinances as of September 4, 2020. Tom Geist <tom.geist@tobacco21.org> (last accessed September $4^{\text {th }}$, 2020).
} 
8. Sensitivity Analysis: State-level little and large cigar taxes from the CDC State System. ${ }^{32}$ For each class of cigars, states either use an ad valorem tax or an excise tax, and both variables are controlled separately.

9. Sensitivity Analysis: State-level ENDS product packaging laws from the Public Health Law Center. ${ }^{35}$

- Laws affecting availability of substitutes/complements:

1. The state's beer tax, ${ }^{36}$

2. Indicator for presence of a state vertical ID law for youth (Nesson and Shrestha 2021), ${ }^{37}$

3. Indicators for state medical (Anderson and Rees 2021) and recreational ${ }^{38}$ marijuana laws, and

- Economic climate: ${ }^{39}$

1. The unemployment rate,

2. The percent of residents living below the poverty line.

- For a sensitivity analysis, National Center for Health Statistics (NCHS) urban-rural classification schemes are controlled as a sensitivity analysis. ${ }^{40}$

\footnotetext{
${ }^{35}$ Public Health Law Center. U.S. E-cigarette Regulations - 50 State Review. Available at: https://www.publichealthlawcenter.org/resources/us-e-cigarette-regulations-50-state-review (last accessed $4 / 1 / 2022)$.

${ }^{36}$ Urban Institute \& Brookings Institution. State Alcohol Excise Taxes. Available at: https://www.taxpolicycenter.org/statistics/state-alcohol-excise-taxes (last accessed April 13 ${ }^{\text {th }}, 2021$ ). ${ }^{37}$ We supplemented data from this paper with newer dates: Minnesota (8/2018), Missouri (12/2012), New York (1/2013), Oregon (12/2018), and Tennessee (7/2018).

${ }^{38}$ Marijuana Policy Project. State Laws with Alternatives to Incarceration for Marijuana Possession. Available at: https://www.mpp.org/assets/pdf/issues/decriminalization/State-Decrim-Chart.pdf (last accessed April 13 ${ }^{\text {th }}, 2021$ ).

${ }^{39}$ University of Kentucky Center for Poverty Research. (2021, Feb.). UKCPR National Welfare Data, 1980-2019. Lexington, KY. Available at http://ukcpr.org/resources/national-welfare-data (last accessed April 13 ${ }^{\text {th }}$, 2021). ${ }^{40} 2013$ NCHS Urban-Rural Classification Scheme for Counties. Available at: https://www.cdc.gov/nchs/data_access/urban_rural.htm. (last accessed June $7^{\text {th }}$, 2021).
} 
Online Methods Appendix: Discussion of the use of TWFE regression to estimate causal parameters with a continuous treatment variable

Our treatment variable follows a staggered adoption, that is jurisdictions adopt ENDS taxes at different points in time. Recent econometric literature shows that this treatment regime can lead to bias in regression coefficients in TWFE estimators when treatment effects are heterogenous across treated units or time (Goodman-Bacon 2021). The source of this bias is “forbidden comparisons” (Borusyak, Jaravel, and Spiess 2022). In the binary treatment variable case, TWFE coefficient estimates can be decomposed in to all possible $2 * 2$ difference-indifferences comparisons. Some of these comparisons will be "reasonable" in that newly treated units are compared to untreated units. However, some comparisons will be "forbidden:” those that compare newly treated units to previously treated units. If treatment effect heterogeneity is present (e.g., treatment effects grow over time after the tax is adopted), then the latter type of comparison can lead to negative weighting and possibly sign-reversals. The recent economic literature has developed both tools to diagnose this issue (Goodman-Bacon 2021) and methods that are robust to bias attributable to heterogeneity and dynamics in treatment effects (de Chaisemartin and D’Haultfoeuille 2022; Callaway and Sant’Anna 2021; Borusyak, Jaravel, and Spiess 2022). ${ }^{41}$ However, our treatment variable is continuous which adds complexity; thus, one could view our estimator as a generalized difference-in-differences estimator. At the time of

\footnotetext{
${ }^{41}$ The empirical importance of this bias is of course context specific. A common theme of recent estimators developed to address bias from heterogeneity and dynamics in treatment effects is selecting "clean" comparison groups. That is, only untreated units are included in the comparison group, thereby circumventing issues related to "forbidden" comparisons. Another limitation of using TWFE regressions to estimate causal effects with a staggered treatment regime is the estimator's weights. TWFE regression models place the most weight on observations for which treatment "turns on" in the middle of the panel. This is an artifact of the OLS minimization procedure which upweights observations with the most variance in the treatment variable. If there is heterogeneity in treatment effects, weighting in this manner can lead to a regression coefficient that departs from the average treatment effect on the treated which is an object of interest in applied microeconomics. To address this weighting issue, estimators in this new literature allow the researcher to select their own weights.
} 
writing, the econometric literature is only beginning to offer tools to address this setting (Callaway, Goodman-Bacon, and Sant’Anna 2021).

With a continuous (or multi-valued) treatment variable, there are more objects of potential interest to the researcher. As noted by Callaway, Goodman-Bacon, and Sant’Anna (2021), there are at least four parameters salient to applied microeconomics questions: 1 ) average treatment effect on the treated (ATT), 2) average treatment effect (ATE), 3) average causal response on the treated (ACRT), and 4) average causal response (ACR) ${ }^{42}$ Callaway, GoodmanBacon, and Sant'Anna (2021) introduce the concept of “dose” in estimation of continuous treatment variable effects, the dose of the treatment is simply the intensity of treatment, in our context is the size (in dollars) of the ENDS tax. The ATT and ATE are "level" effects in that they provide an estimate of the effect of a specific dose level (e.g., \$1.00) relative to zero dose (\$0.00). These target parameters are reasonable in the binary treatment setting as there is just one treatment dose: treated vs. untreated. On the other hand, ACRT and ACR are "slope" effects in that they reveal the effect of an incremental change in treatment dose on the outcome (e.g., $\$ 1.00$ increase in the ENDS tax from $\$ 0.50$ to $\$ 1.50) .{ }^{43}$ Our parameter of interest in our study is the ACRT.

Recovery of a causal estimate of the ACRT requires the researcher to make certain assumptions which we now list and then discuss in our context; see Callaway, Goodman-Bacon, and Sant'Anna (2021) for a full discussion of these assumptions. The first is random sampling. We expect that our data satisfy this assumption given that we rely on two nationally

\footnotetext{
${ }^{42}$ Callaway, Goodman-Bacon, and Sant'Anna 2021 build upon seminal work by Angrist and Imbens 1995 and motivate their discussion based on the "average causal response function." The average causal response function captures pairs of doses (X-axis) and ATT's (Y-axis). That is, one can read off the value of the ATT for each possible dose of treatment. The ACRT is the slope of the average causal response function if the treatment variable is continuous and a line connecting the ACRT curve for adjacent dose values if the treatment variable is multivalued. ${ }^{43}$ Comparable to the binary case, the ATE and ACR recover estimates for the full population while the ATT and ACRT recover estimates for the treated sub-population.
} 
representative surveys. The second is support, meaning there must be jurisdictions at the actual dosage levels we are examining. Practically, this assumption implies that we are estimating across particular discrete ATT points; that is, the points that correspond to tax values that are levied in jurisdictions in our sample and not other values. Third, there are no anticipation effects, meaning treatment (i.e., ENDS tax adoption) cannot have effects prior to the tax being levied. ${ }^{44}$ Thus, we assume that youth in our sample do not change their tobacco product purchasing and associated behaviors prior to the tax change. If youth are myopic and/or do not pay attention to government tax policy discussions in their locality (versus adopted taxes), then this assumption seems reasonable. The fourth assumption is parallel trends. However, we must assume a different version of parallel trends than is required with a binary treatment variable. Callaway, GoodmanBacon, and Sant’Anna (2021) refer to this assumption as “strong parallel trends”: all groups that receive treatment at the same time (regardless of dose) would have followed the same path of potential outcomes at every possible dose level. Thus, strong parallel trends places restrictions on treated potential outcomes, not just untreated potential outcomes as in case of a binary treatment regime. ${ }^{45}$

With these four assumptions, we are able to recover an estimate of the ACR, but not the ACRT; instead, we recover an estimate of the ACRT plus a selection bias term, where the selection relates to states (or rather decision makers in states) selecting their level or dose of the treatment (ENDS taxation level in our context). ${ }^{46}$ To recover a causal estimate of the ACRT, we

\footnotetext{
${ }^{44}$ Assuming no anticipation is sub-subsumed by the stable unit treatment value assumption (SUTVA), which states that observed outcomes for a unit in a time period are determined by that unit's treatment in that time period.

${ }^{45}$ In the canonical difference-in-differences set-up, the researcher assumes that the treatment and comparison group would have followed the same trends in outcomes, post-treatment, had the treatment group not been treated. This assumption only restricts the path of untreated potential outcomes.

${ }^{46}$ In particular, we recover the following with the four above-noted assumptions: $\operatorname{ACRT}\left(\mathrm{d}_{\mathrm{j}} \mid \mathrm{d}_{\mathrm{j}}\right)+$ [(ATT $\left.\left(d_{j-1} \mid d_{j}\right)-\operatorname{ATT}\left(d_{j-1} \mid d_{j-1}\right)\right]$. The first term is the object of interest (the ACRT for dose $d_{j}$ within the group
} 
assume that selection bias is zero. This assumption is potentially reasonable if individual youth tobacco product consumption decisions (our outcomes) are not the driving factors that drives state policy makers to adopt specific values of ENDS taxes. We attempt to provide suggestive evidence on the extent to which this assumption is reasonable. To this end, we extend the concept of "balance testing." Using the Monitoring the Future data (MTF), one of two data sets we use in our main analyses, we divide the sample into groups of ENDS tax jurisdictions that had taxes as of the $2^{\text {nd }}$ quarter of 2019 (when our study ends) of $\$ 0$, $\$ 0.01$ to $\$ 1.00, \$ 1.01$ to $\$ 2.00$, and $\$ 2.00$ to $\$ 2.52$ (the highest tax in place) and compare tobacco product use and demographics of youth at baseline (year 2014). While current ENDS use rates are quite stable across groups, we see evidence that higher ENDS tax adopting locations have higher Hispanic share. If Hispanic share is related to selection into treatment dose, then our results may be interpreted most conservatively as an estimate of the ACR parameter. However, if other factors (for example, youth use of tobacco products) are more salient for selection into dose (that is, the factors that policymakers consider when establishing ENDS tax rates), then we may be less concerned about selection into dose in our setting and thus our findings may be interpreted as an estimate of the ACRT parameter.

In our manuscript, we rely upon TWFE regression to estimate the ACRT. Thus, we impose the admittedly strong assumptions noted above. While these assumptions are strong, we do demonstrate that results are broadly similar using the multiperiod difference-in-differences estimator proposed by de Chaisemartin and D'Haultfoeuille (2022) which is reassuring. We also

\footnotetext{
of treated units that received dose $d_{j}$ ). The second term is the selection bias: the difference in ATTs (recall that the average causal response function is the collection of ATT and dose pairs) at dose $d_{j-1}$ for groups that received dose $\mathrm{d}_{\mathrm{j}}$ and $\mathrm{d}_{\mathrm{j}-1}$. Therefore, by assuming that the selection bias term is zero we are asserting that the ATT for the different groups that chose different dose levels $\left(d_{j}\right.$ and $\left.d_{j-1}\right)$ would have had the same ATT if they had instead both chosen the same dose $\left(d_{j-1}\right)$.
} 
show that results are robust to the use of a modified stacked difference-in-differences estimator that allows for different doses of treatment, which is another approach used in the empirical microeconomic literature in the context of a continuous treatment (Rees, Sabia, and Margolit 2021). However, at the time of writing, there is no consensus on how best to address the continuous treatment case. As econometric methods continue to develop, it will be interesting for the health economics community to re-examine the impact of ENDS taxation on youth vaping and smoking, and other research questions that exploit variation in continuous treatment variables. 